\title{
The Impact of Surface Treatments on the Architectural Formation of Green Buildings "Comparative Study of some Contemporary Global Models"
}

\author{
Eng. Osama N. Abd El-Majeed \\ Postgraduate Student in the Field of Engineering Sciences; Department of \\ Architecture, Faculty of Engineering, Ain Shams University, Cairo, Egypt. \\ Prof. Dr. Hussam H. El-Barambali, Ph.D \\ Professor of Architectural Design and Urban Conservation; Department of \\ Architecture, Faculty of Engineering, Ain Shams University, Cairo, Egypt. \\ Prof. Dr. Akram F. Muhammad, Ph.D \\ Professor of Architecture and Project Management; Department of Architecture, \\ Faculty of Engineering, Ain Shams University, Cairo, Egypt.
}

\section{Abstract:}

The research study is based on the principle of "analysis and comparison" between the selected samples from foreign projects in terms of some important points represented in: Definition of the building from the perspective of: (its location, type, date of implementation, classification, and architectural designer), in addition to the various treatments inside the buildings from the perspective of : (Environmental and architectural "climatic" elements, green architecture design thinking, and the use of Xeriscape format). This is in preparation for extracting some important results and recommendations for global experiences that interacted with technologies in the field of green architecture through their buildings at the present time, as these global models were classified as follows:

- The EDITT Tower:

A model of a universal building executed at the end of the twentieth century.

\section{- Boston Fusion, Kohinoor Skyscraper:}

Models of international buildings that were implemented at the beginning of the twenty-first century.

\section{- Green Towers in the Park:}

A model of a universal building it will be implemented at the beginning of the twenty-first century.

Keywords: Green Architecture, Xeriscape Format, Global Experiences. 


\section{تأثير معالجات الأسطح على التشكيل المعماري للمباني الخضراء "دراسة مقارنة لبعض النماذج العالمية المعماري المعاصرة"}

م. أسامة نورالاين عبد المجيد طالب در اسات عليا في مجال العلوم الهندسية؛ قسم العمارة، كلية الهندسة، جامعة عين شمس، القاهرة، مصر. أ.د. حسام الدين حسن عثمان البرمبلي أستاذ التصميم المعماري والدين والحفاظ العمر البري؛ قسم العمارة، كلية الهندسة، جامعة عين شمس، القاهرة، مصر.

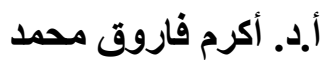
أستاذ العمارة وإدارة أدمارة المشروعات؛ قسم العمارة، كلية الهندسة، جامعة عين شمس، القاهرة، مصر. ملخص البحث: تعتمد الدر اسة البحثية على مبدأ "التحليل والمقارنة" بين العينات المختارة من المشـرو عات الأجنبية من حيث

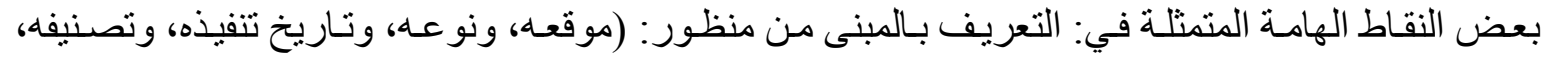

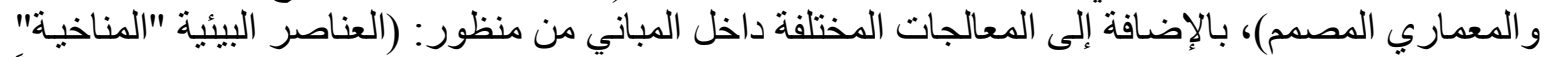

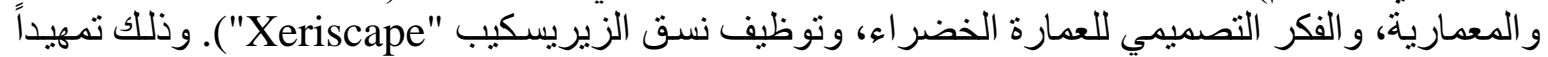

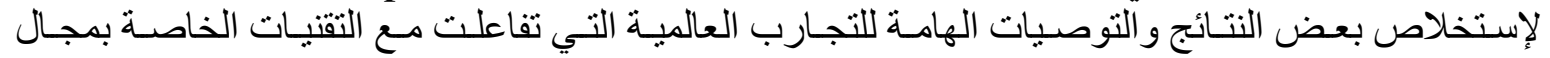
العمارة الخضر اء من خلال مبانيها في الوقت الحالي، حيث تم تصنيف هذه النماذج العالمية على النحات النحو التالي:

$$
\begin{aligned}
& \text { • برج إديت: لمبنى عالمي نم تنفيذه في نهايات القرن العشرين. }
\end{aligned}
$$

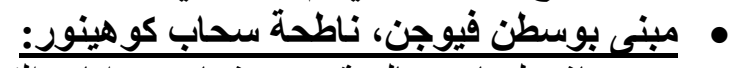

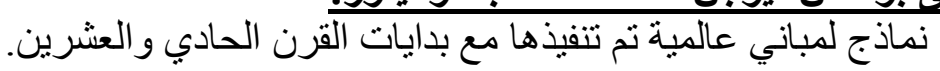

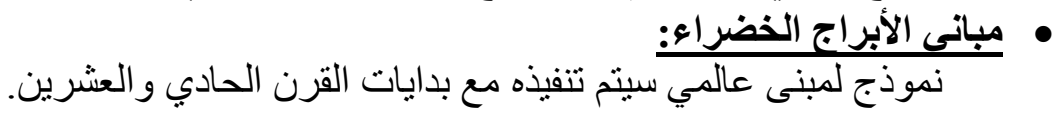

$$
\begin{aligned}
& \text { الكلمات الدالة: العمارة الخضر اء، نسق الزيريسكيب، التجارب العالمية. }
\end{aligned}
$$

ا - - مقدمة البحث:

يعتبر فكر معالجات الأسطح في المستوبين الأفقي والر أسي للمبنى من أبرز المشكلات التي يمكن ملاحظتها

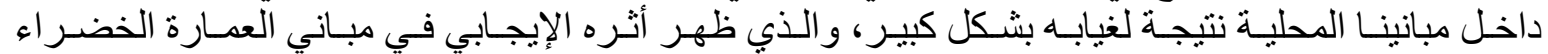

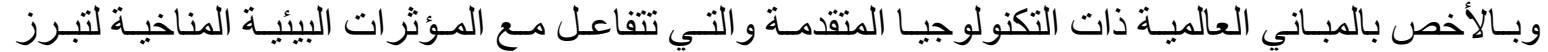

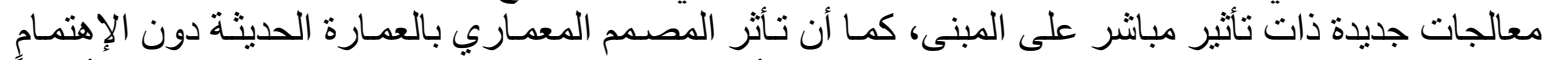

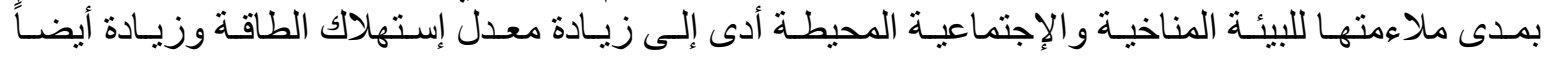

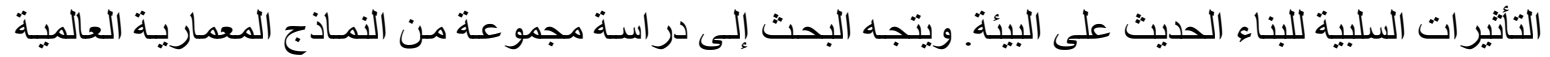

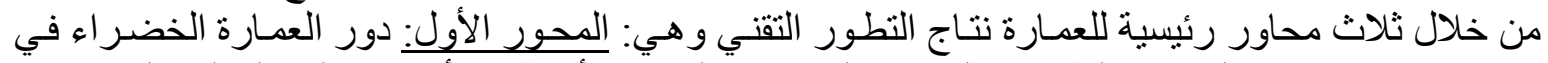

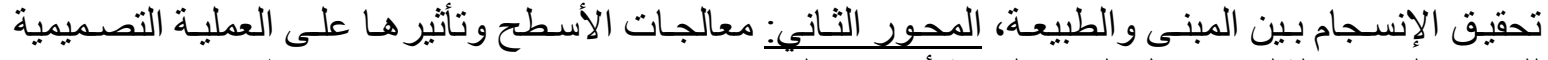

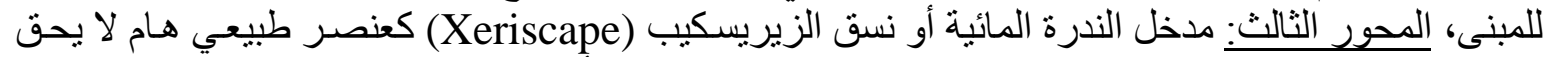

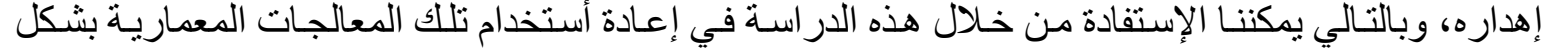

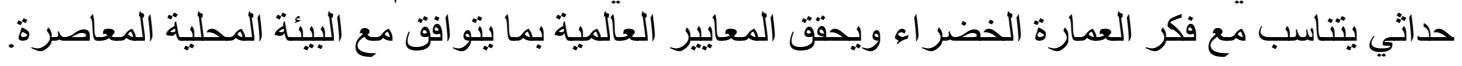

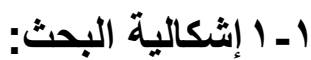

و وتتمثل في: "غياب فكر معالجات الأسطح في الاتجاهين الأفقي والرأسي للمبنى عن واقعنـا المحلي المعاصر

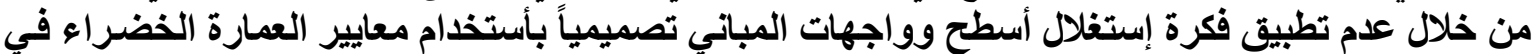

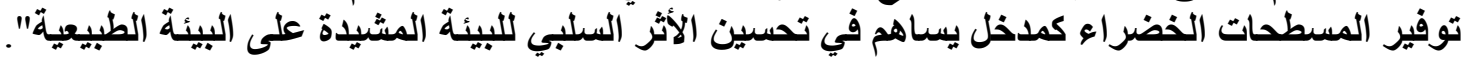


تهدف الاراسة في هذه الورقة البحثية إلى تحقيق ما يلي:

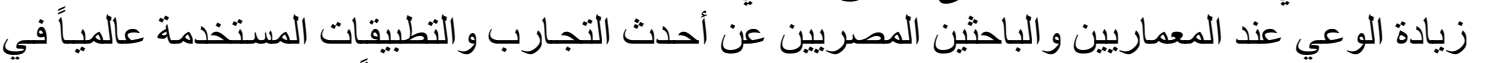

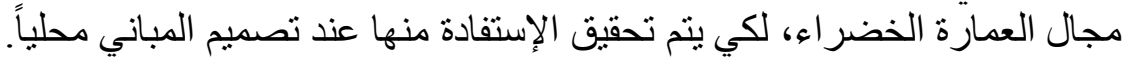

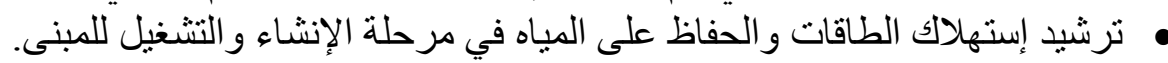

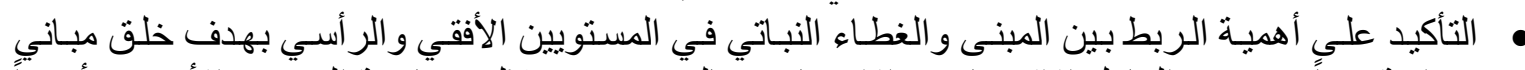

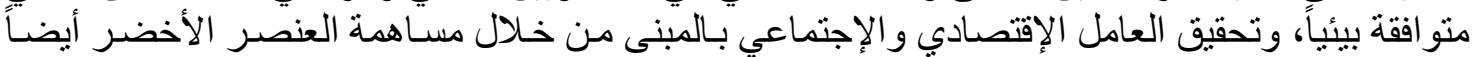
في توفير الإحتياجات المادية وغير العامل الإنهائة للمستخدمين.

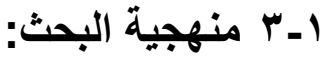

يتبع البحث في هذه الدر اسة "المنهج التحليلي" الذي يعتمد على الدر اسات العالمية السـابقة والحديثة في مجال

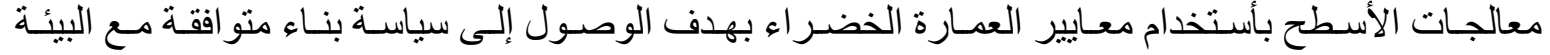
ومواكبة للتطور التقني في مجال العمارة داخل مبانينا المحلية المعاصرة.

r- أسس إختيار الحالات الدراسية:

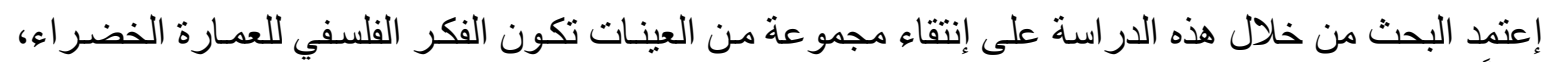

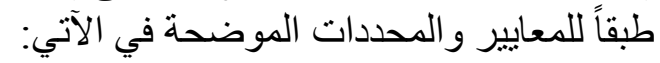

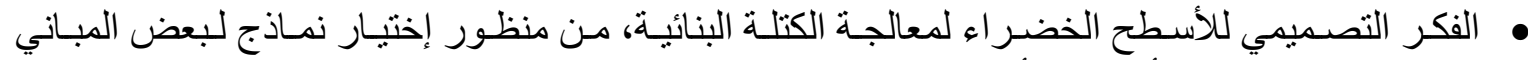

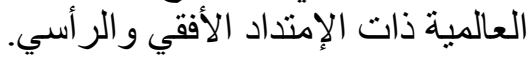

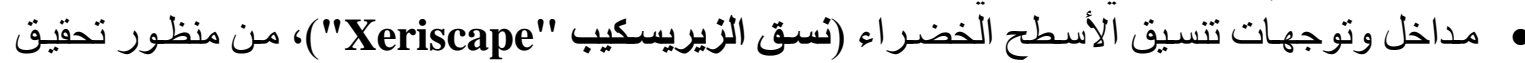
التكامل بين المبنى والعنصر النباتي، و الحفاظ على المياه المستخدمة في عملية ري النباتات.

ب- مقارنة بين الدراسة التحليلية لبعض الأمثلة العالمية المعاصرة:

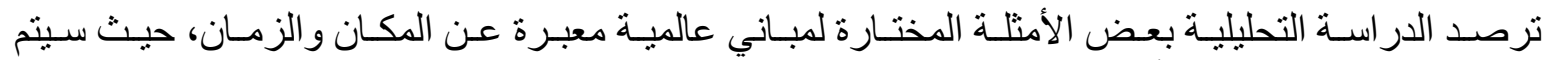

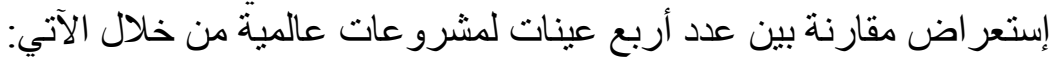

r-1 المثال الأول: برج إديت "The EDITT Tower"

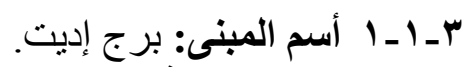

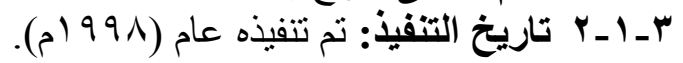

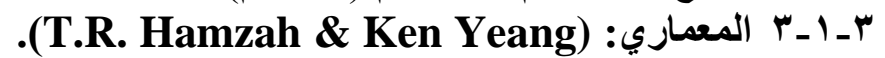

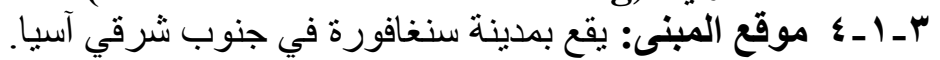

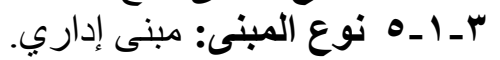

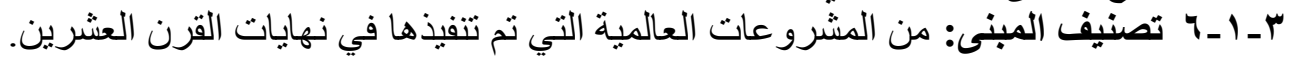

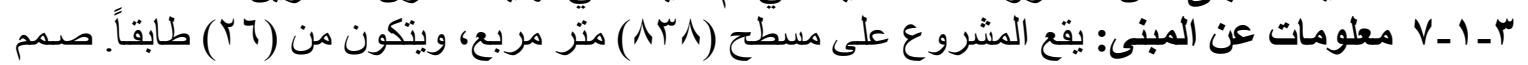

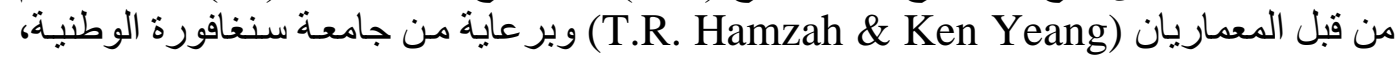

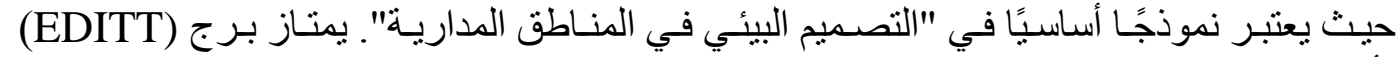

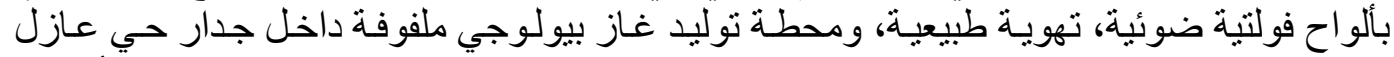

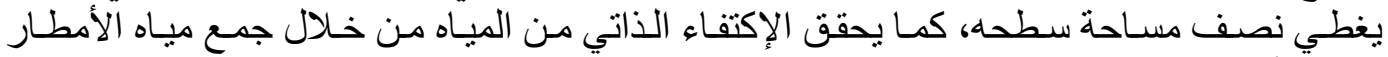

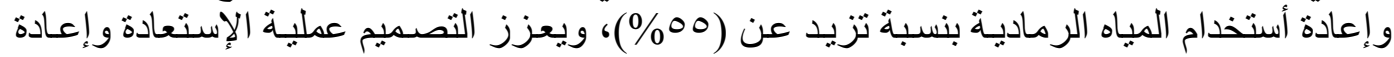

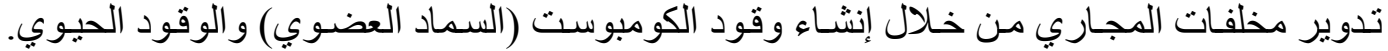

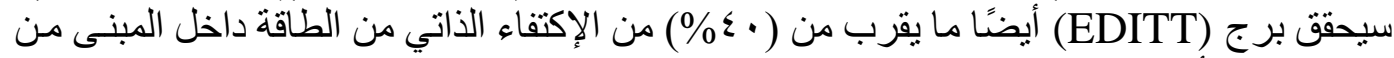

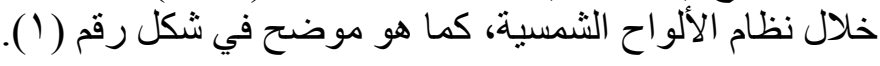




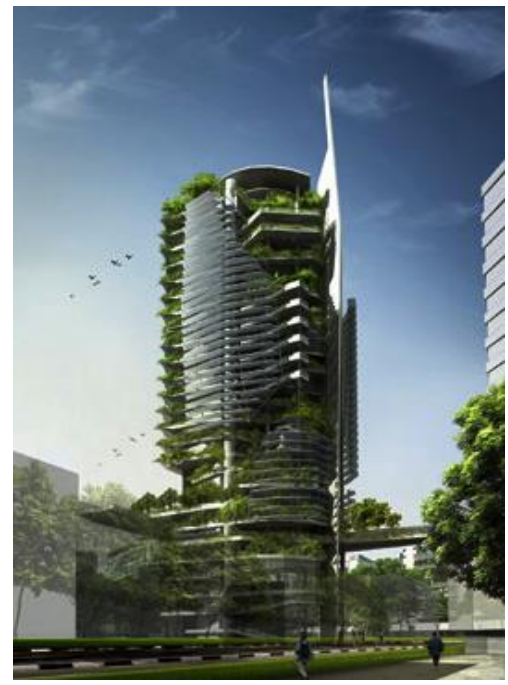

شكل رقم ( ) يوضح برج إديت (The EDITT Tower) الذي يقع بمدينة سنغافورة في جنوب شرقي آسيا،

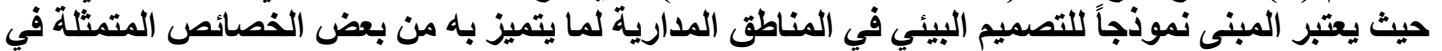

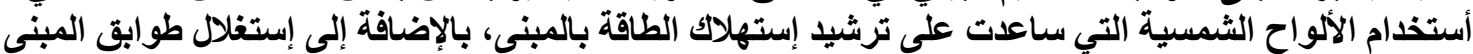

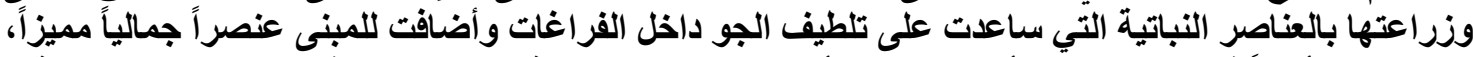

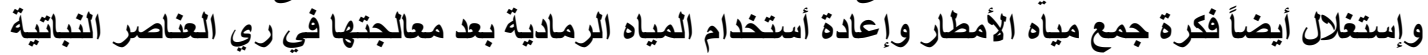

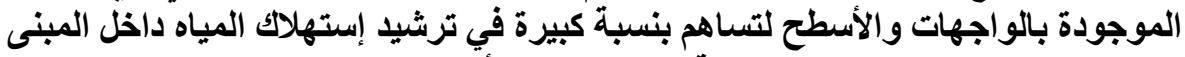

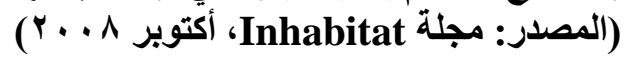

r- ـ ـ أولاً: المعالجة من منظور العناصر البيئية (المناخية) والمعمارية:

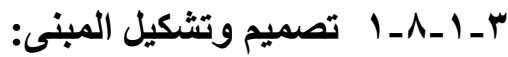

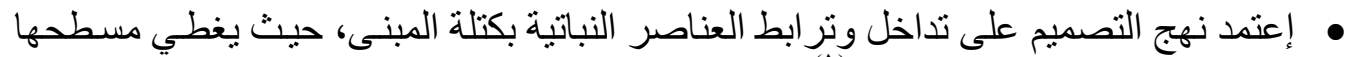

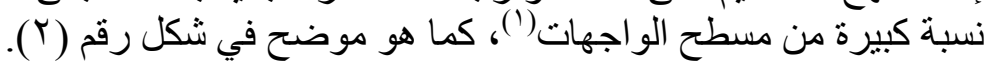

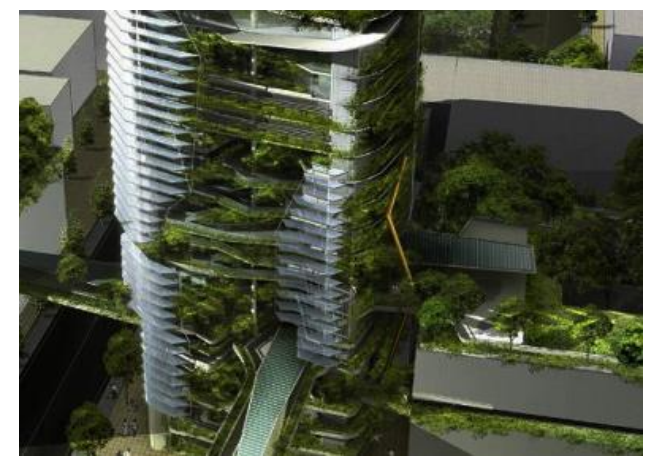

شكل رقم (r) يوضح طريقة تداخل وترابط كتلة المبنى

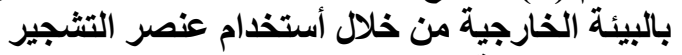

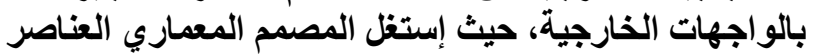

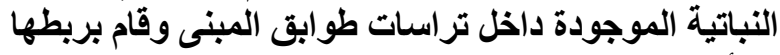

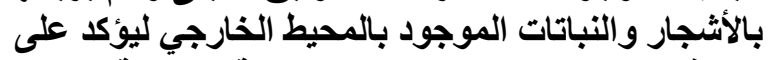

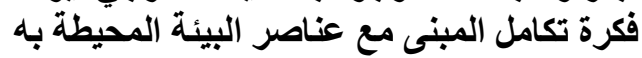

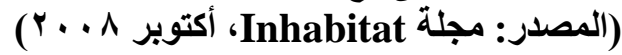

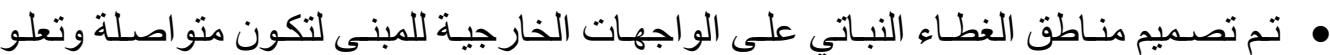

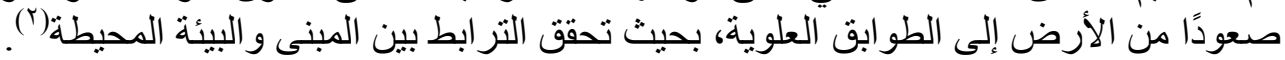

r r_A_l_r

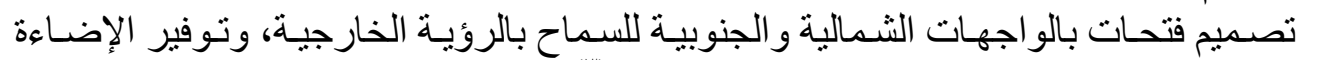

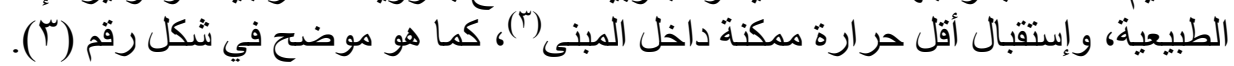




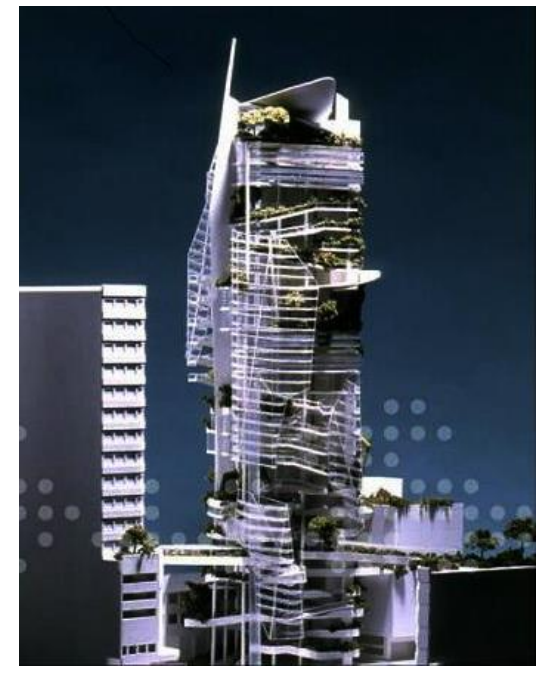

شكل رقم (r) يوضح طريقة توظيف الفتحات بالواجهات لتوفي لتوفير

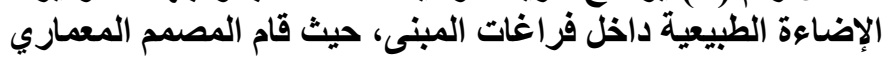

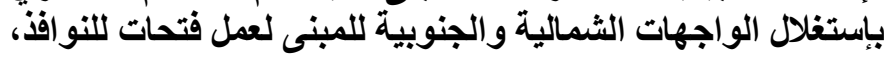

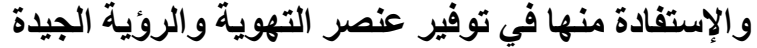

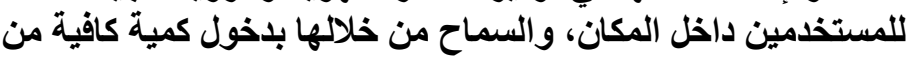

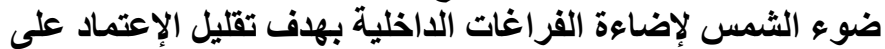

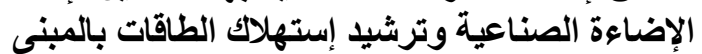

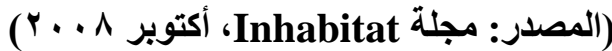

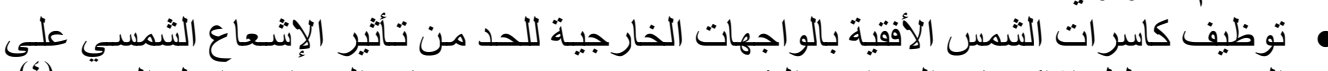

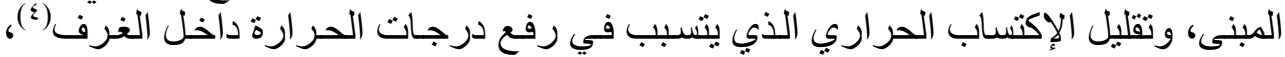

كما هو موضح في شكل رقم (ع) الاكنماب الري

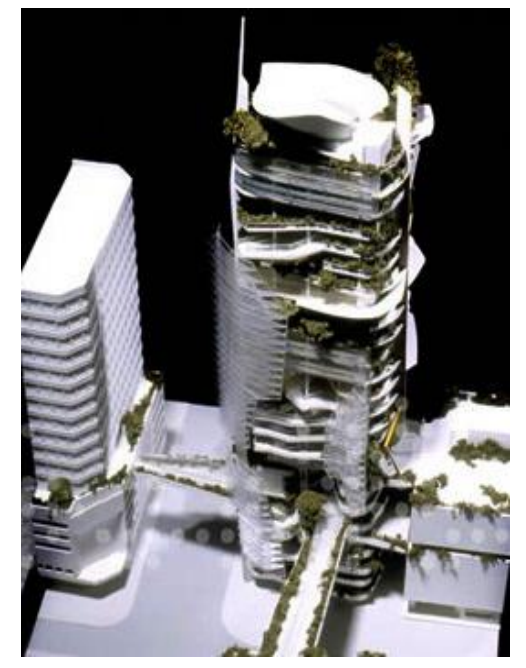

شكل رقم (ع) يوضح طريقة توظيف الكاسرات الثمسية بالو اجهات

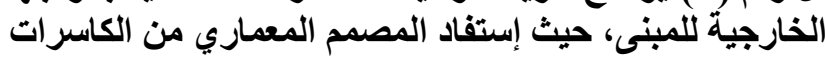

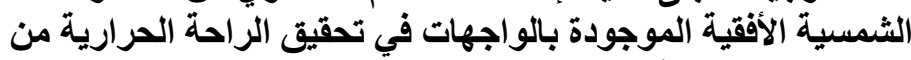

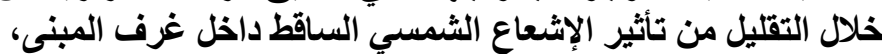

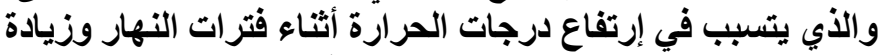
الوهج الثمسي الذي يؤثرعلى روئية مستخدمي المكان

(المصدر: David Gissen, 2003, p.106)

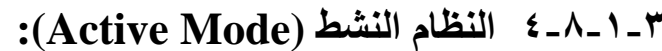

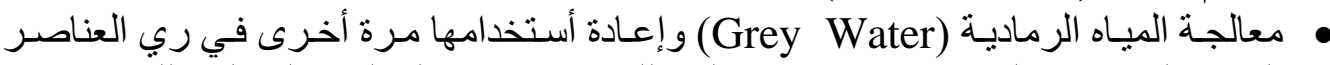
النباتية الموجودة بالمبنى، حيث يترتب على ذلك ترشيد إستهلاك المياه الصناه الصالحة للشرب.

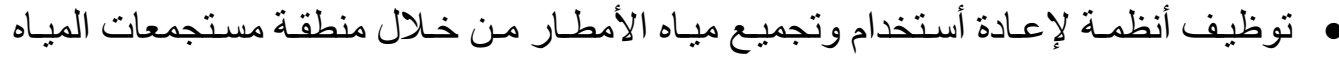
(Roof - Catchments Pan)

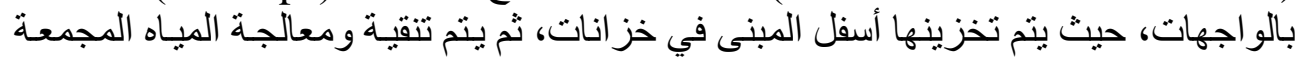
من خـلال نظام تنقيـة الميـاه (Gravity - Fed Water Purification System)، و إعـادة فئه

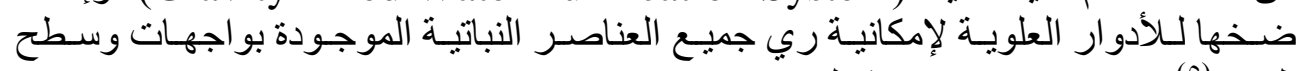

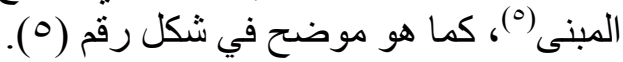




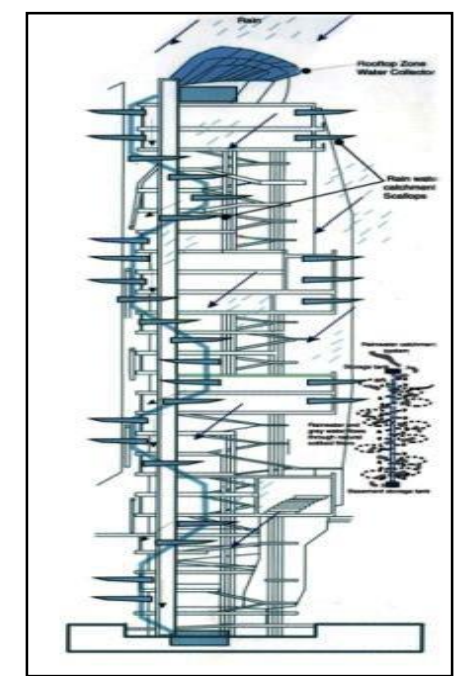

شكل رقم (0) يوضح نظام تجميع وتنقية مياه الأمطار لإعادة أستخدامها

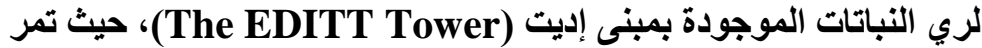

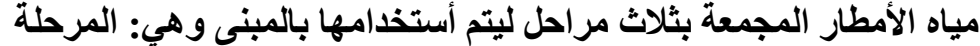

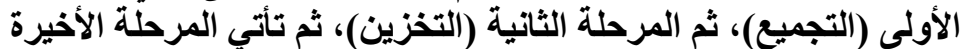

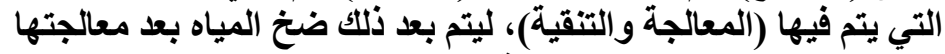

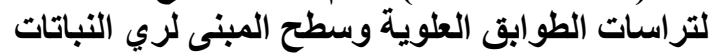

(المصدر: Ivor Richards, 2001, p.113)

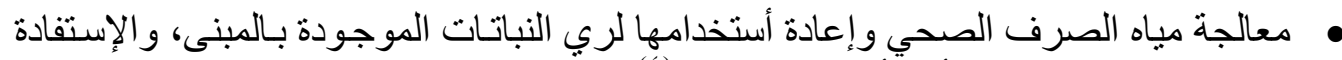

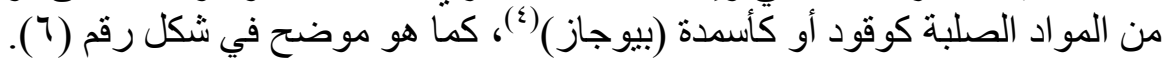

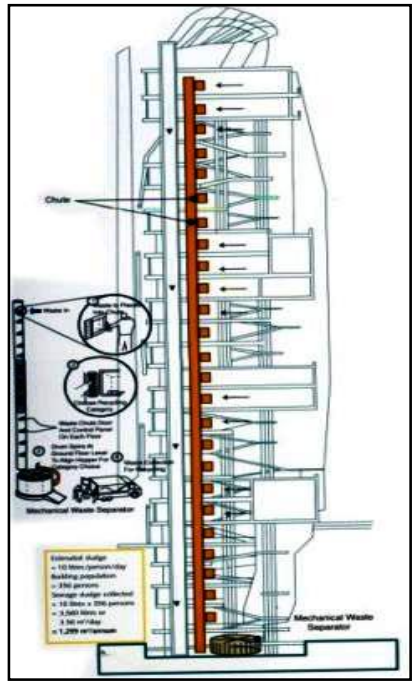

شكل رقم (7) يوضح نظام معالجة مياه الصرف الصحي وإعادة أستخدامها

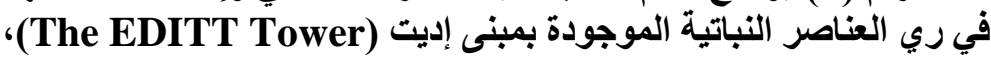

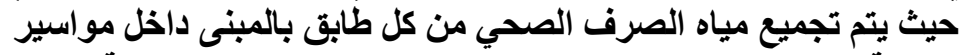

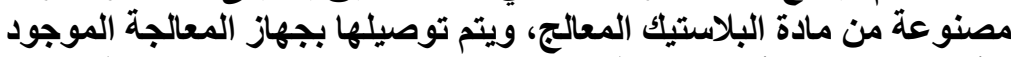

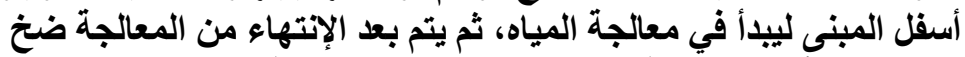

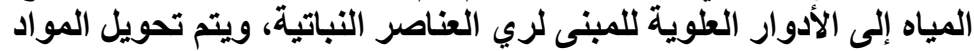

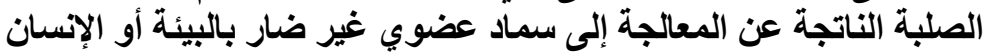

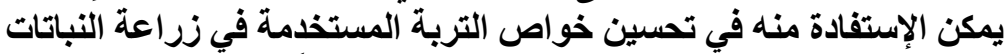

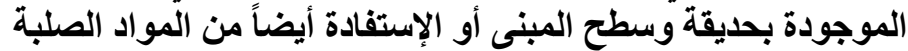

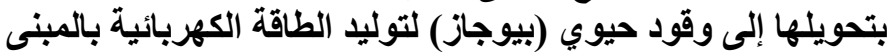
(المصدر: Asmaa Mahmoud, 2008, p.389)

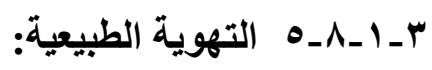

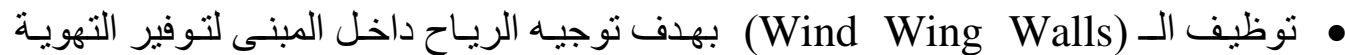

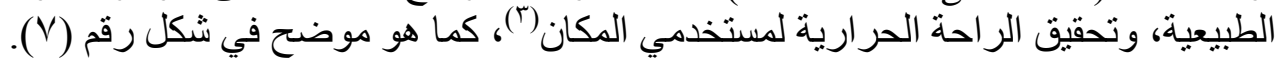

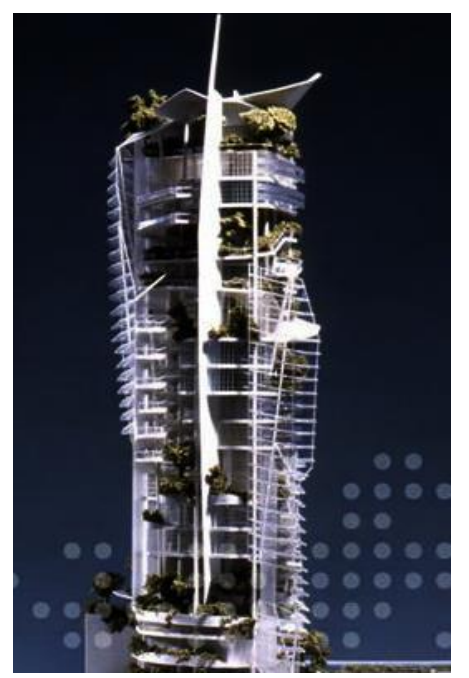

شكل رقم (V) يوضح طريقة توظيف الـ (Wind Wings Walls) لتوفير

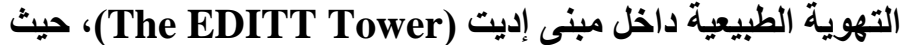
إستفاد المصمم المعماري من فكرة أستخدام الـ (Wind Wing Walls)

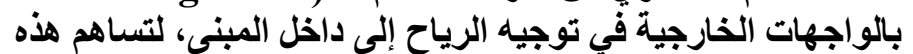

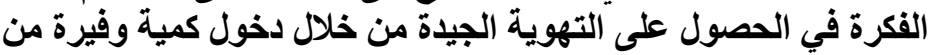

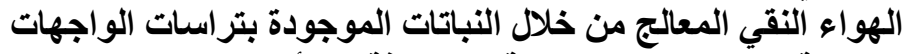

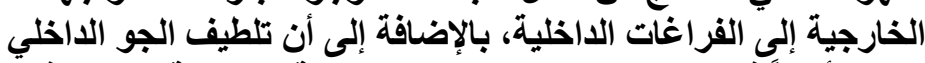

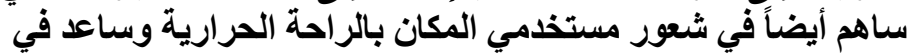

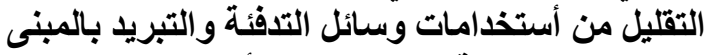

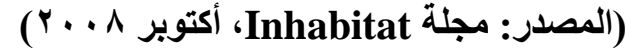




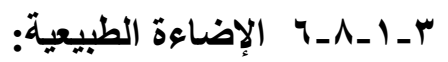

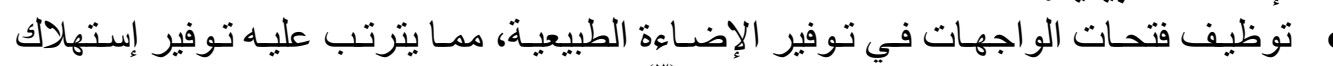

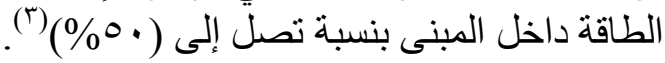

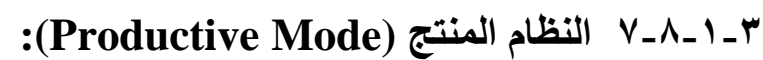

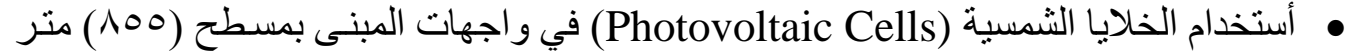

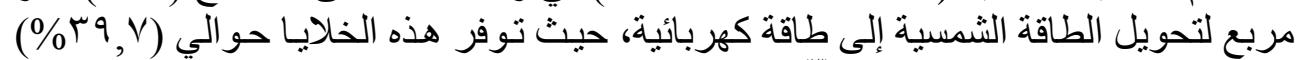

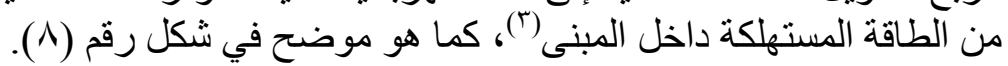

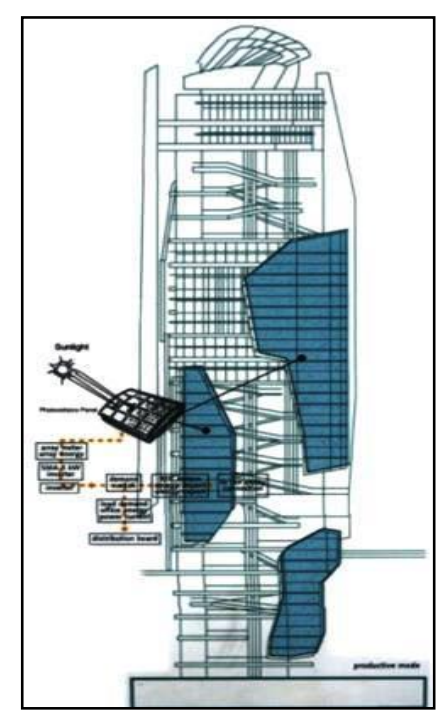

شكل رقم (^) يوضح طريقة توظيف الخلايا الثمسية (The EDITT Tower) في مبنى إديتة (Photovoltaic Cells) لتقليل إستهلاك الطاقة، حيث إستخدم المصمم المعماري الخلايا

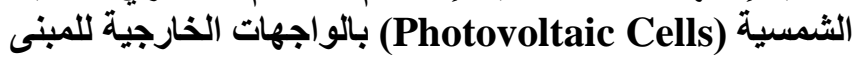

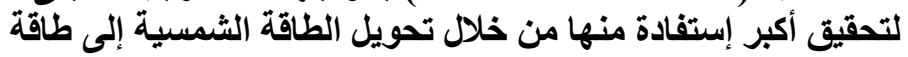

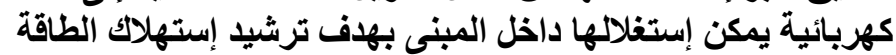

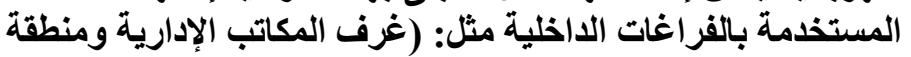

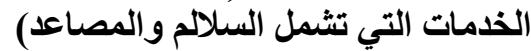

(المصدر: Ivor Richards, 2001, p.113)

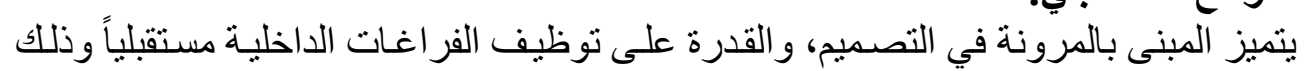

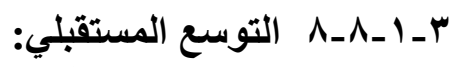

$$
\text { ( ) إعادة توظيف التوصيلات الميكانيكية. }
$$

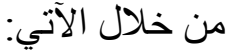

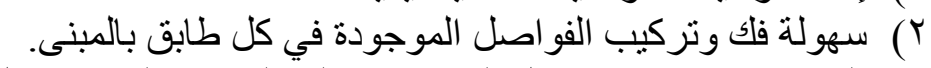

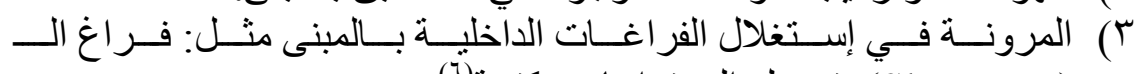

بتحويله إلى فر اغات مكتبية) (Skycourts)

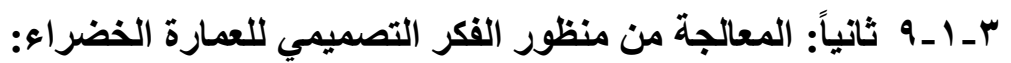

• تقليل الإكتسـاب الحراري للفراغـات الداخليـة من خـلال أستخدام الكاسـرات الثمسية بالو اجهات الخارجية و التوجيه الجيد الجيد للمبنى.

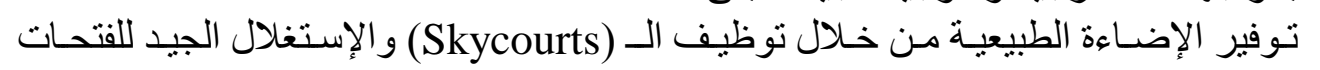
الموجودة بالو اجهات الخارجية.

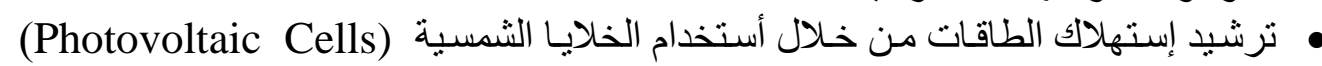
بو اجهات المبنى لتحويل الطاقة الثمسية إلى طاقة كهرب الثبائية.

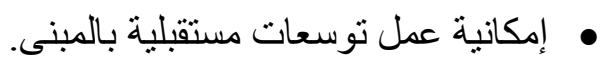

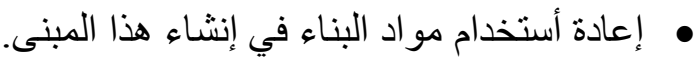
• وجود نظام تجميع وتنقية مياه الأمطار و إعادة أستخدامها في ري النباتات الموجودة بالمبنى. 
• توفير التهوية الطبيعية للفر اغات الداخلية من خلال:

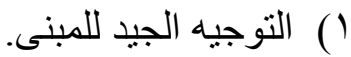

(Y) (Y) أستخدام الـ (Wind Wing Walls).

r) ت بنكيل الطو ابق وتداخل كتل المبنى.

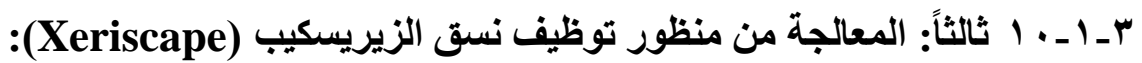

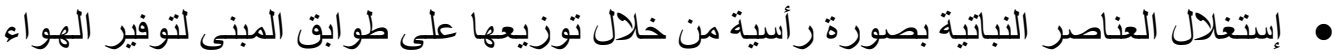

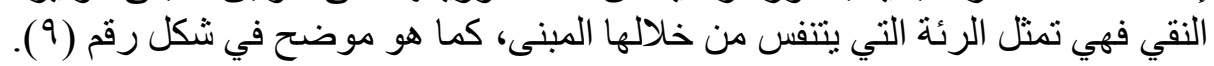

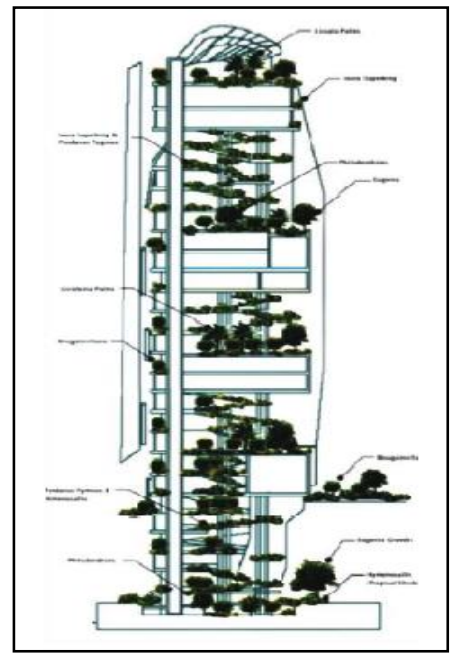

شكل رقم (9) يوضح طريقة توظيف العناصر النباتية بالو اجهات

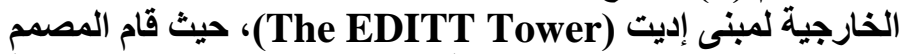
المعماري بتوزيع النباتات المقاومة للجفاف داخل التراسات الخارجية التباية

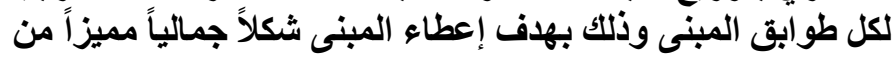

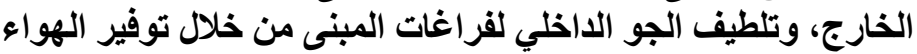

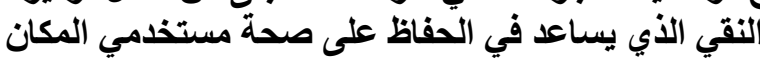

(المصدر: Ivor Richards, 2001, p.110)

نسبة العناصر النباتيـة المقاومة للجفاف بالنسبة لكتلة المبنى نسبة جيدة، حيث تم توزيعها

على هيكل المبنى من الخارج وربطها بالبيئة المحيطة، كما هو موضح في شكل رقم (• (1).

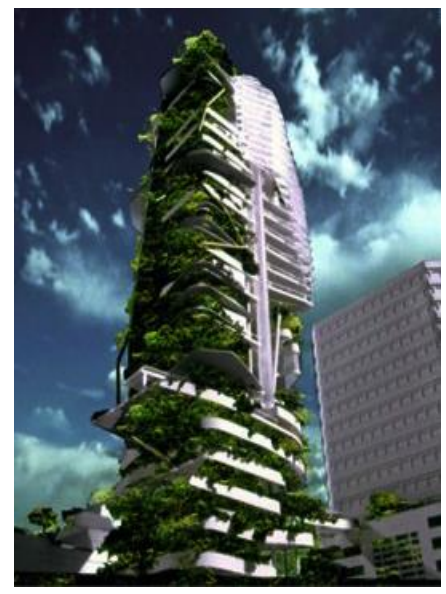

شكل رقم ( • 1) يوضح التكافؤ بين كتلة المبنى والغناصر النباتية

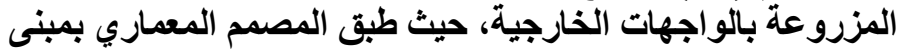

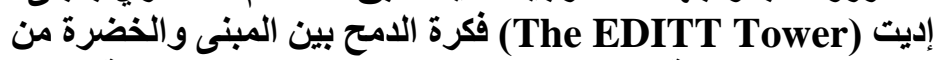

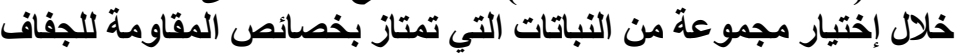

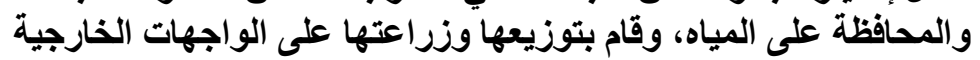

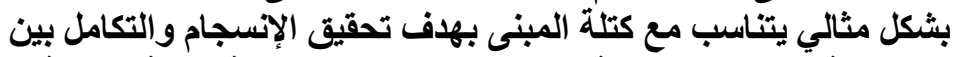

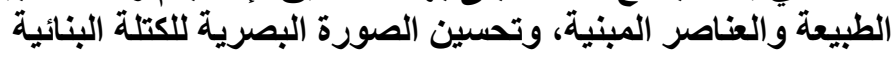

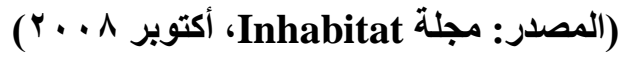

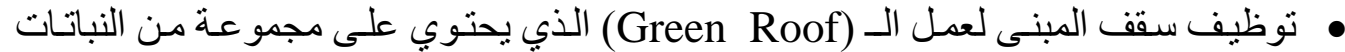

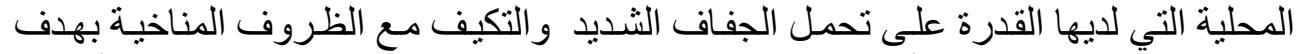

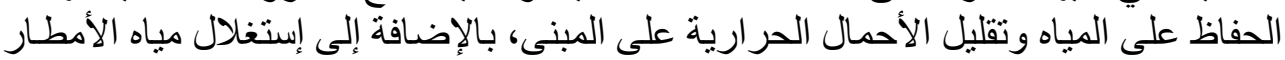
في عمليات الري، كما هو موضح في شكل رقم (1'). 


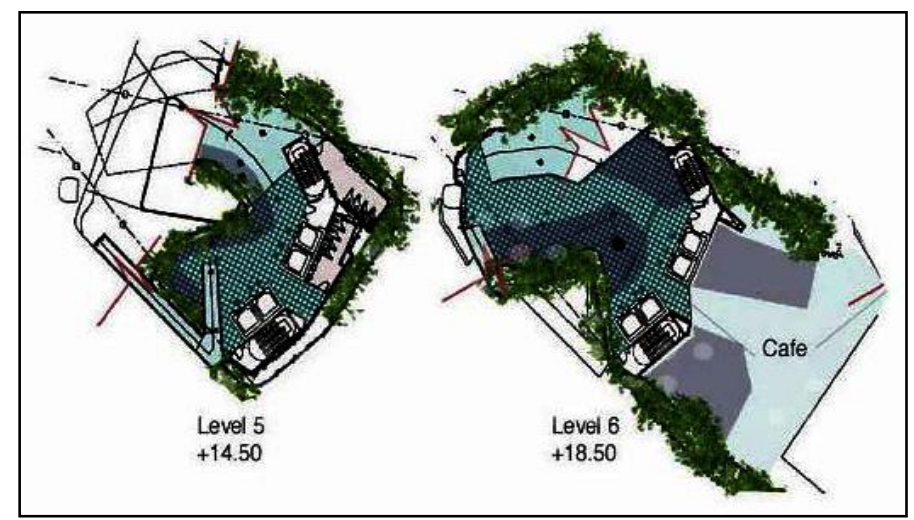

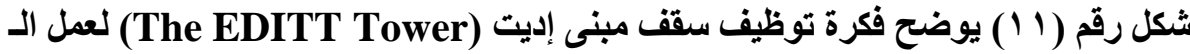

(Xeriscape) (Green Roof)

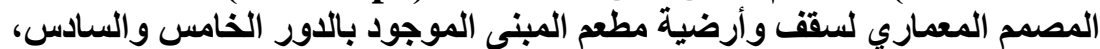

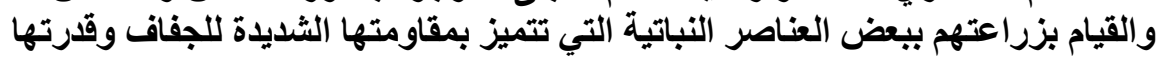

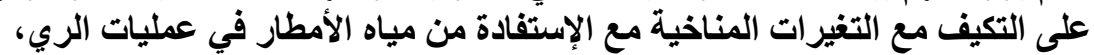

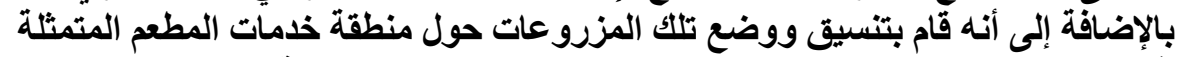

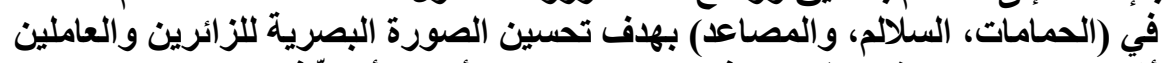

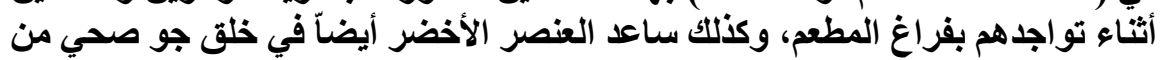

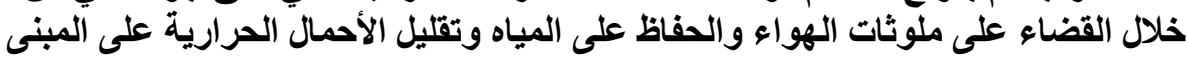

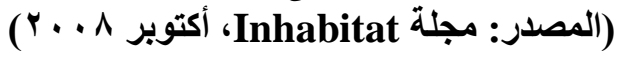

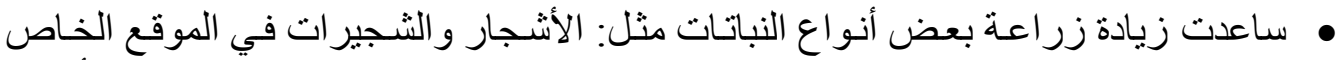

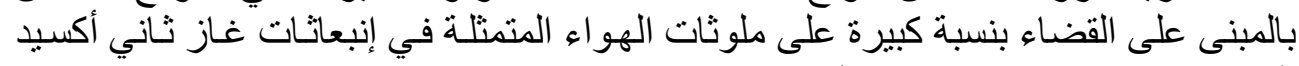

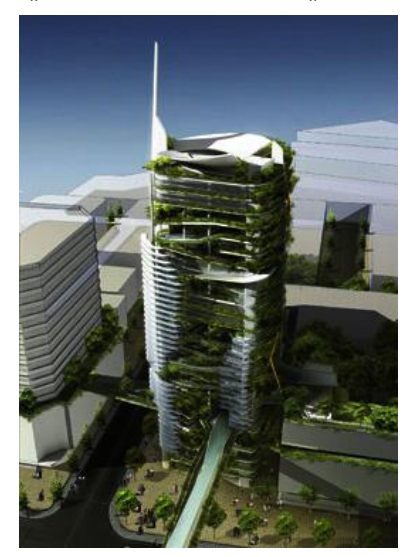

الكربون، كما هو موضح في شكل رقم (r) (I ).

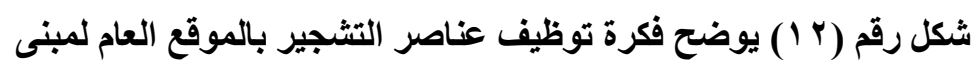

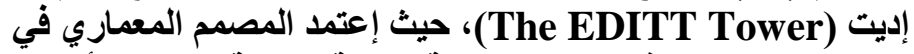

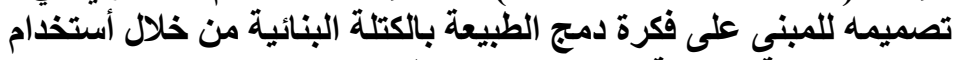

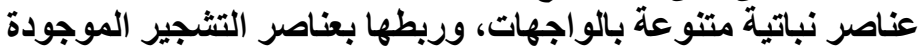

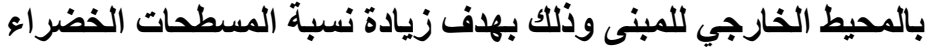

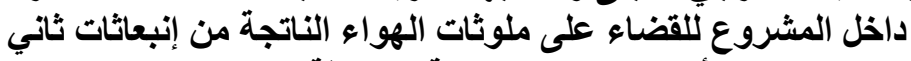

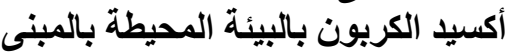

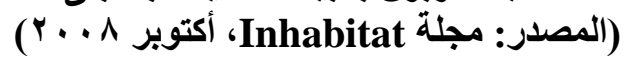

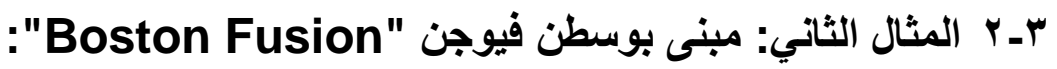

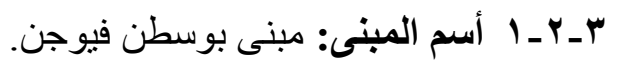

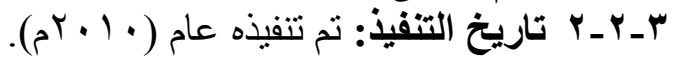

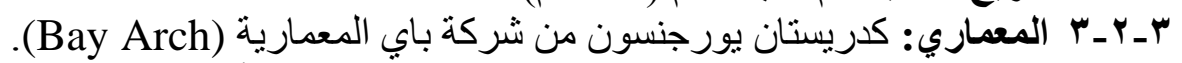

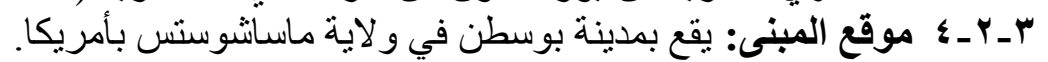

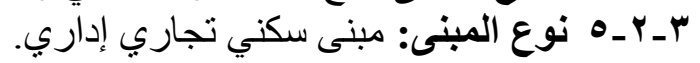

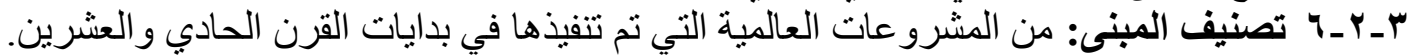
r V_r_r

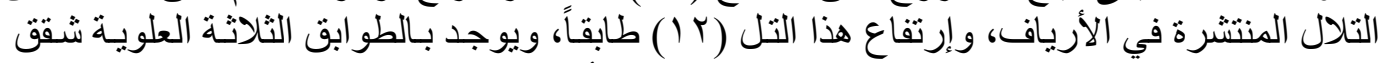

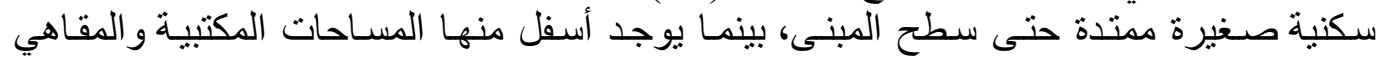




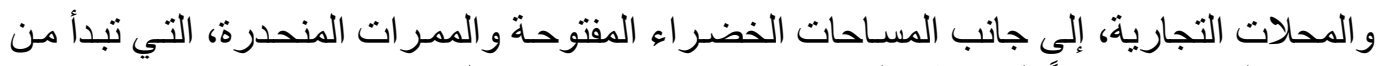

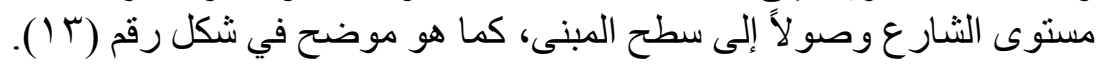

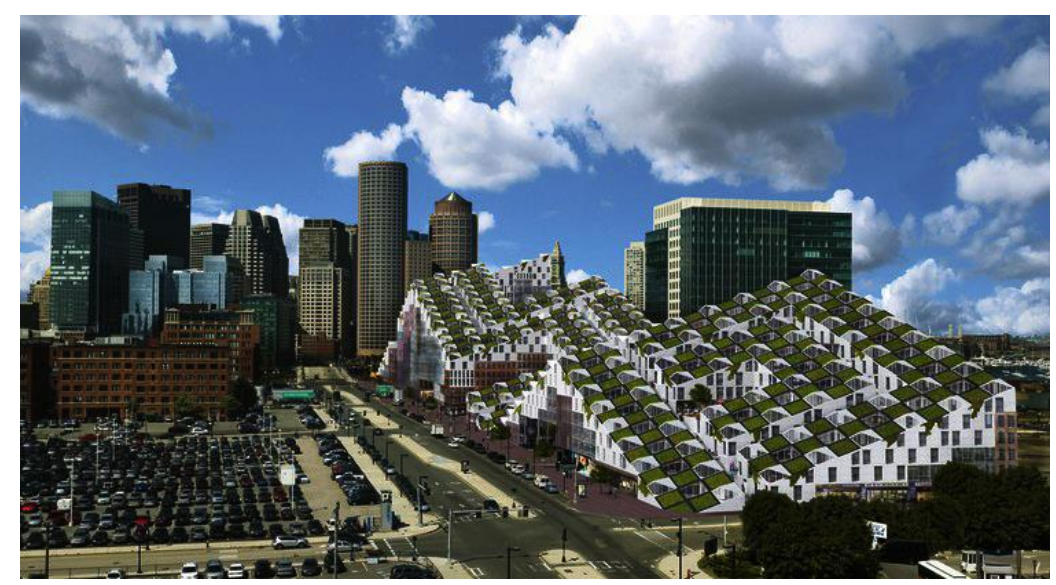

شكل رقم (r ( ) يوضح المساحات الخضر اء التي تلتف من مستوى الثارع حتى سطح مبنى بوسطن

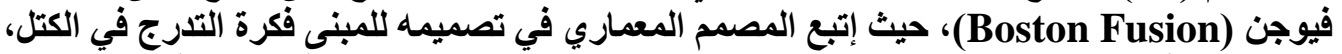

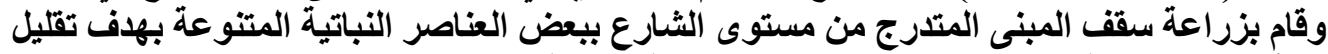

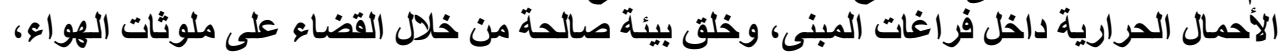

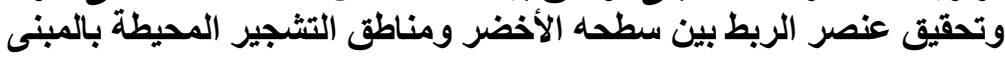

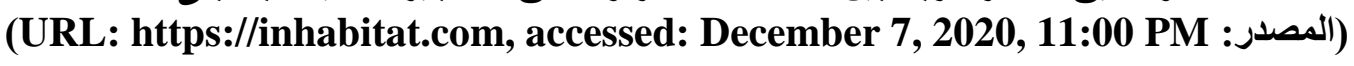

r Y_r_r أولاً: المعالجة من منظور العناصر البيئية (المناخية) والمعمارية:

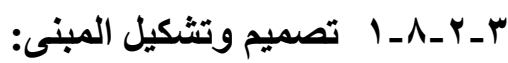

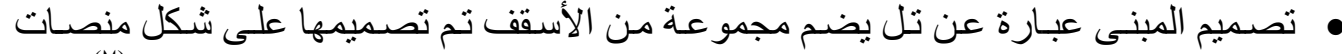

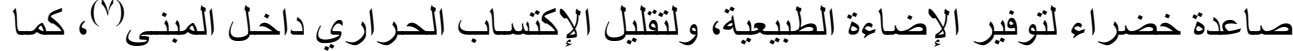

هو موضح في شكل رقم (ع اعند ).

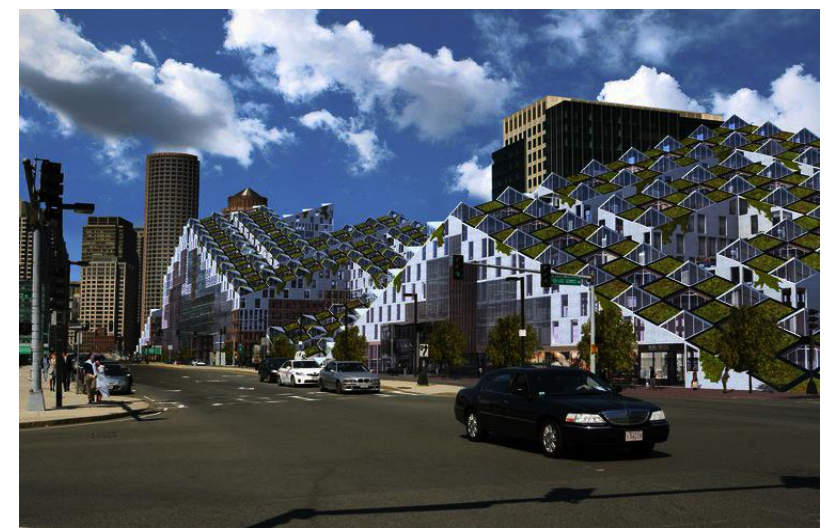

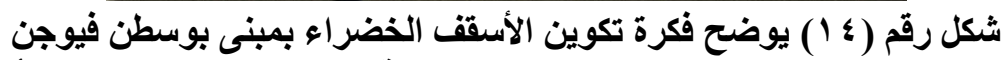

(Boston Fusion)

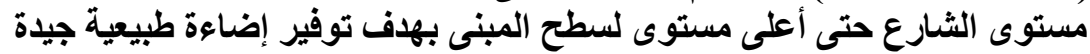

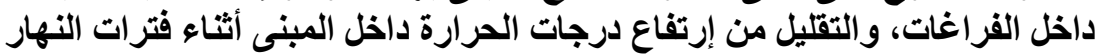

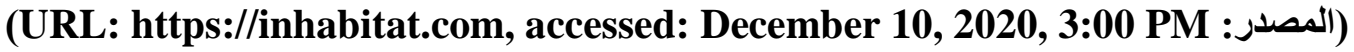

r r-A_r-r

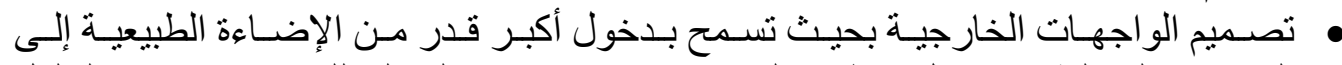

الفر اغات الداخلية من خلال توظيف الـ (Curtain Walls) المعالج للو اجهات بهدف التهاء التقليل 


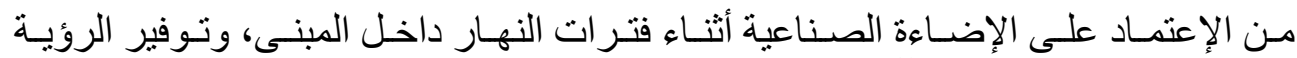
الو اضحة للمحيط الخارجي(1)، كما هو موضح في شكل رقم (10).

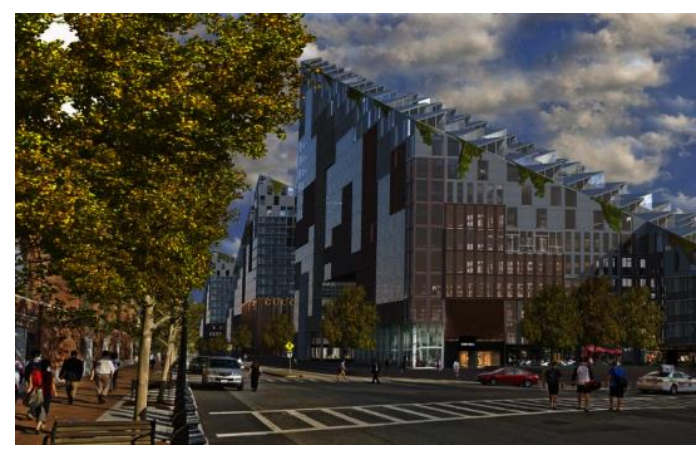

شكل رقم (ه 1 ) يوضح فكرة توظيف الـ Curtain Walls) المعالج لو اجهات مبنى بوسطن فيوجن

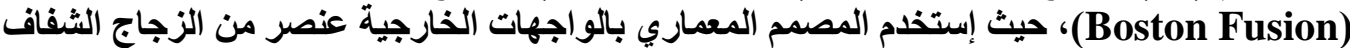

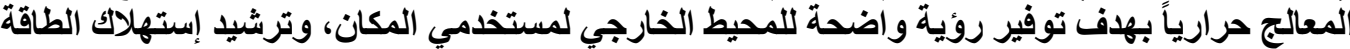
من خلال التقليل من الإكتساب الحراري داخل فراغات المبل المبنى

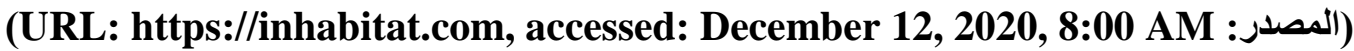

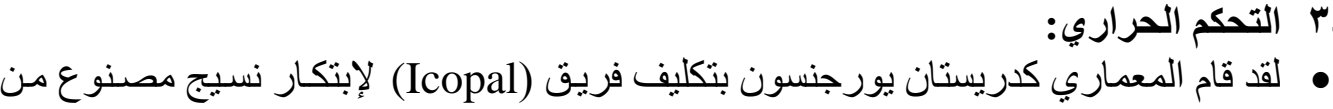
اللباد (مادة مصنو عة من الخشب و الغر اء يتم كبسها لتصبح مستوية) ليغطي السقف الحر التراري

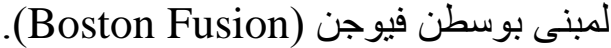

• أستخدام هذه المادة مع العنصر الأخضر سـاعد في تنقية الهواء و التقليل من نسبة التلوث

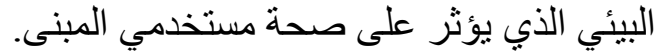

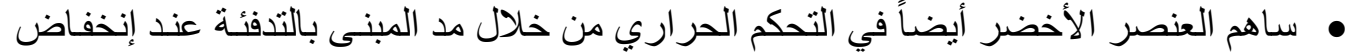

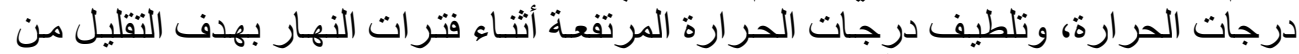
إستهلاك الطاقة داخل المبنى (م)، كما هو موضح في شكل رقم (17 (1).

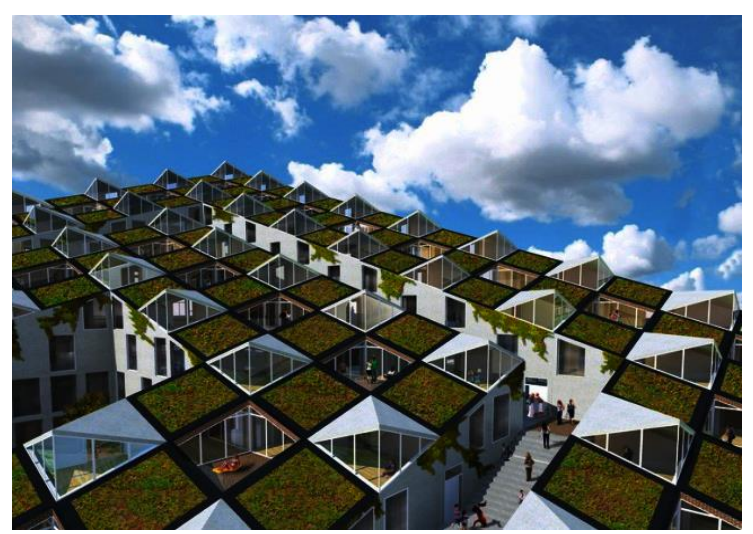

شكل رقم (1 1) يوضح طريقة معالجة السقف الحراري بمنى بوسطن فيوجن (Boston Fusion) من

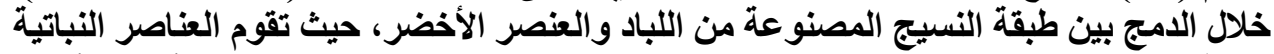

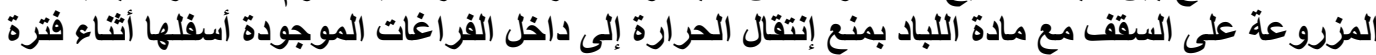

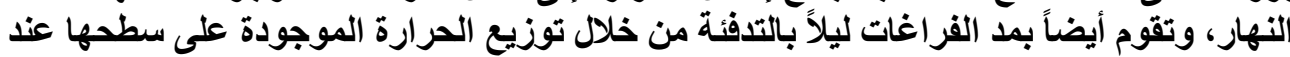

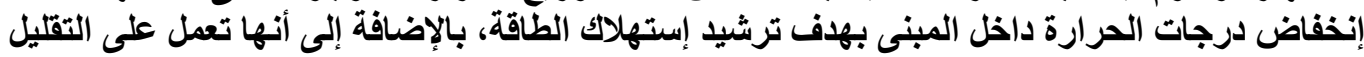
من معدلات تلوث الهواء المحيط بالبيئة الخارجية للمبنى

(URL: https://inhabitat.com, accessed: December 15, 2020, 10:00 PM المصدر: 


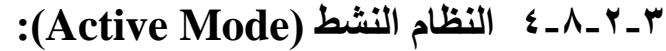

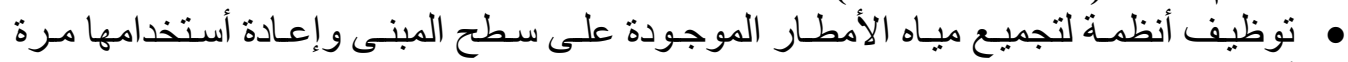

أخرى لري النباتـات من خـال الجزء المسمى بنظام (The Green IcoMoss Roof)

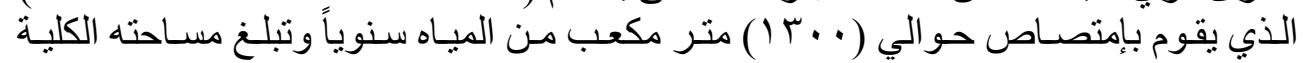

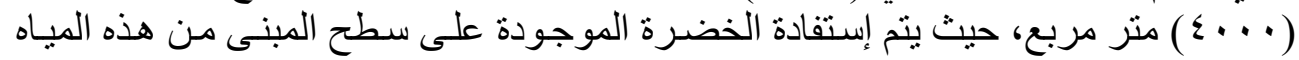

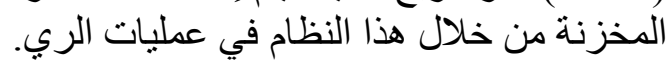

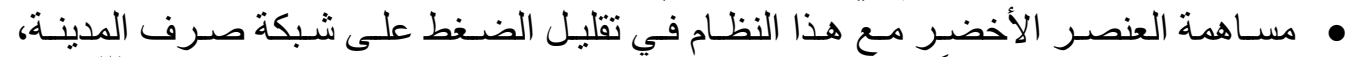

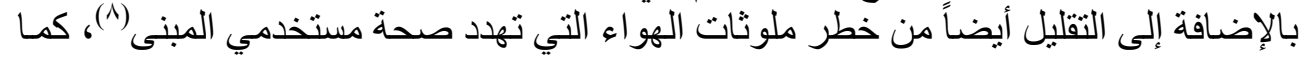

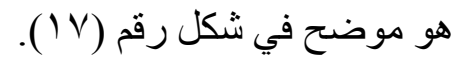

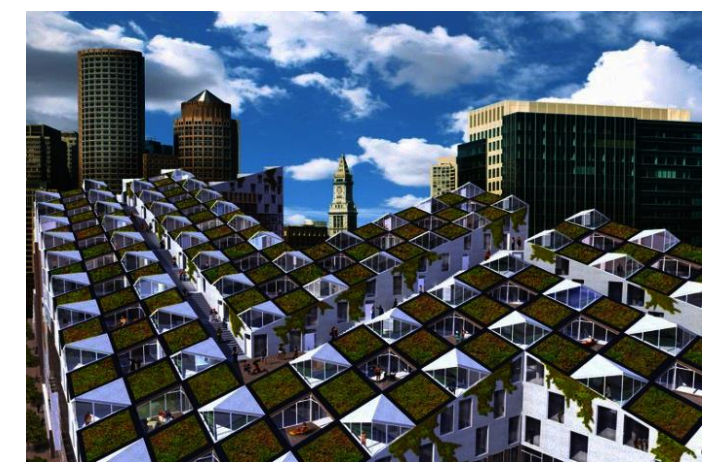

شكل رقم (IV) يوضح طريقة توزيع الخضرة على سطح مبنى بوسطن فيوجن (Boston Fusion)

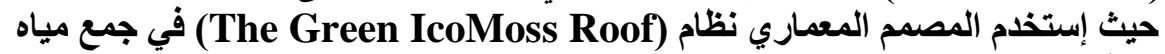

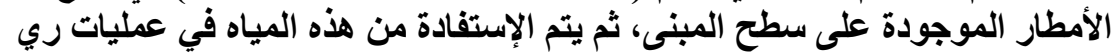

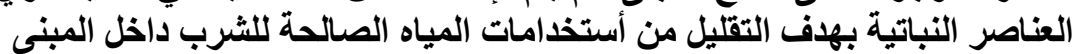

(المصدر: (URL: https://inhabitat.com, accessed: December 16, 2020, 8:00 PM

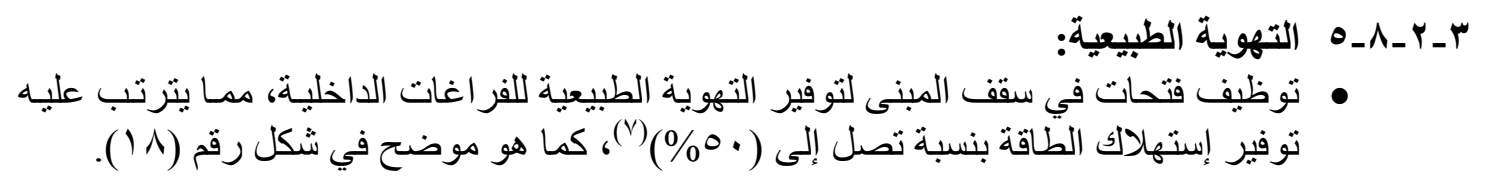

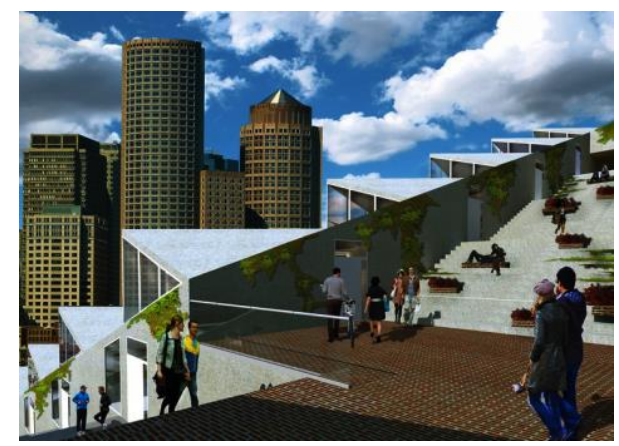

شكل رقم (1 ا ) يوضح طريقة توظيف القتحات لتوفير التهوية الطبيعية داخل مبنى بوسطن

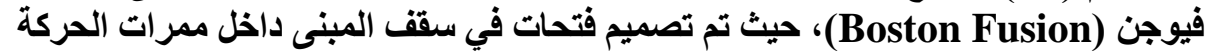

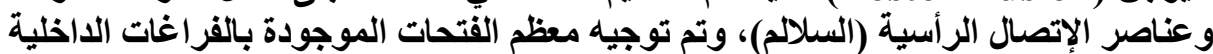

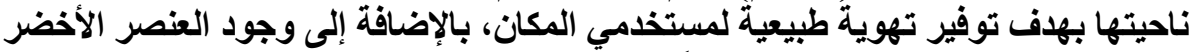

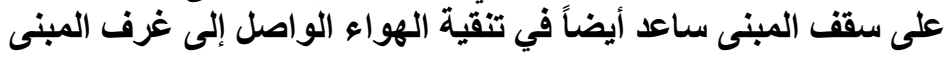

(المصدر: (URL: https://inhabitat.com, accessed: December 16, 2020, 11:00 PM فيناع) 


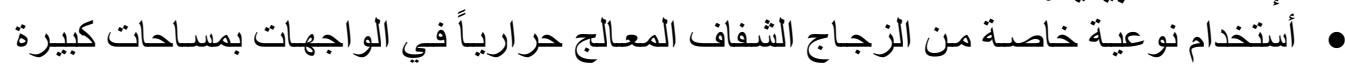

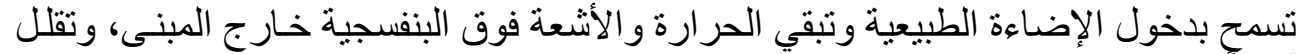

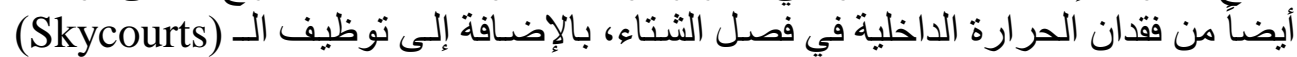

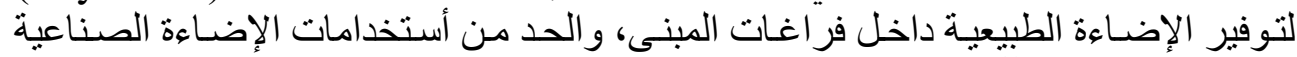

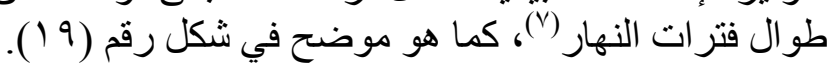
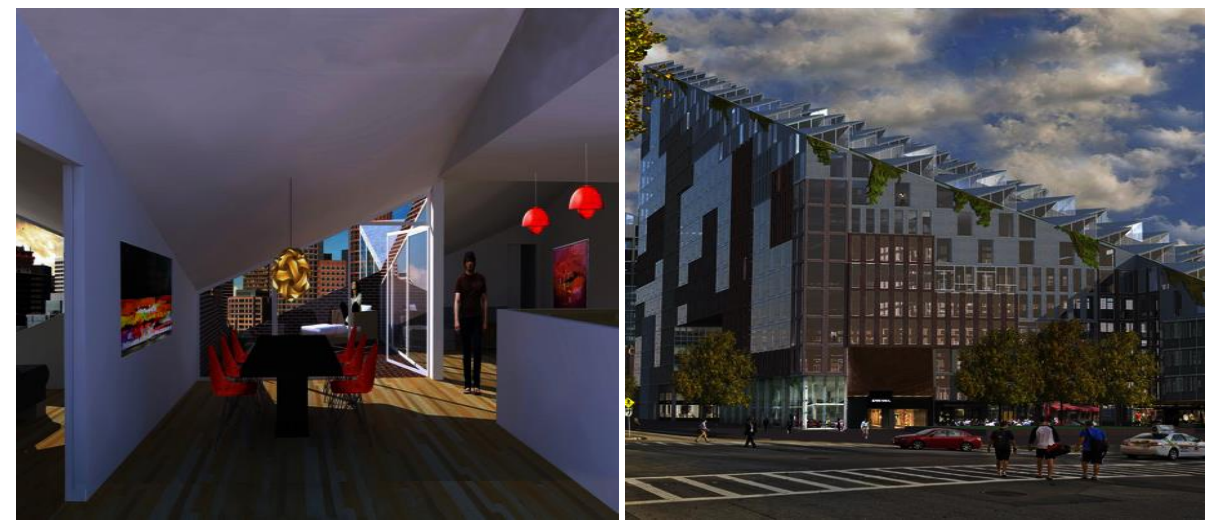

شكل رقم (9 1 ) يوضح أستخدام عنصر الزجاج الثفاف المعالج حرارياً بالواجهات، وتوظيف الـ الـ

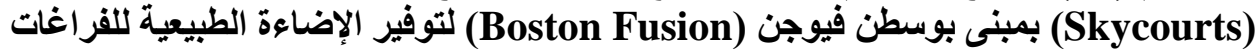

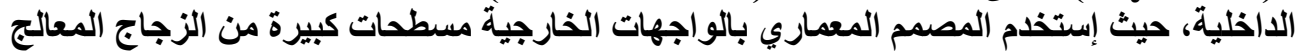

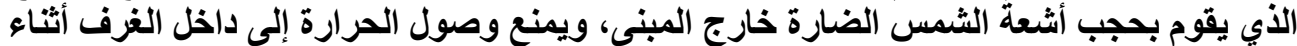

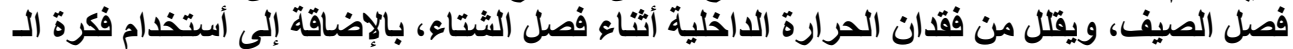

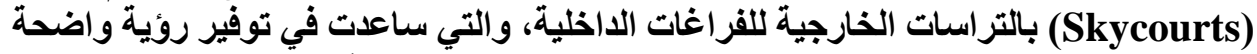

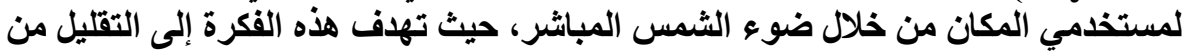

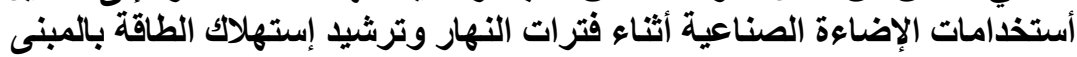

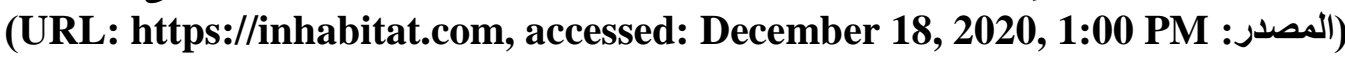

Productive Mode) النظام المنتج V_N_r_r

• إستغلال الطاقة الثمسية وتحو يلها إلى طاقة كهربائية بو اسطة مجمو عـة من الخلايـا الثمسية الصبغية (Dye-sensitized solar cells) التي توجد في السقف الأخضر بهدف تقليل

إستهلاك الطاقة داخل المبنى (^).

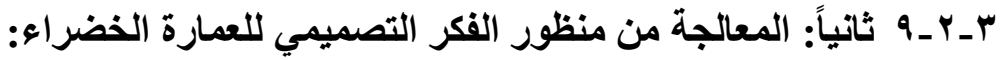

• تـوفير التهويـة الطبيعيـة بالفر اغـات الداخليـة للمبنـى مـن خـلال: التوجيـه الجيـد، وتوظيـف القتحات الموجودة على السطح.

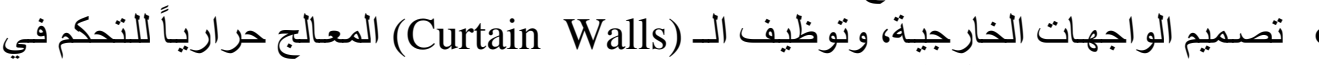

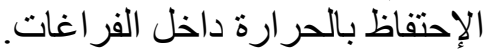

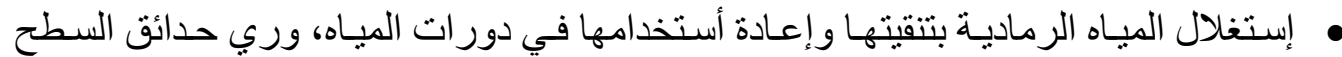

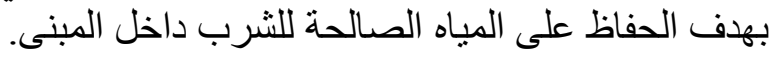

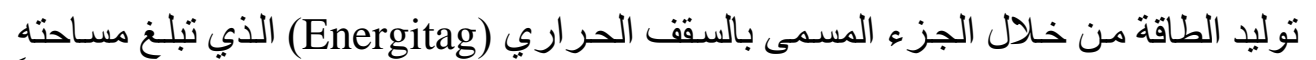

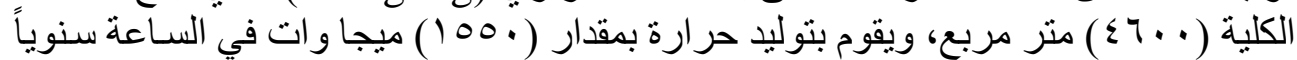

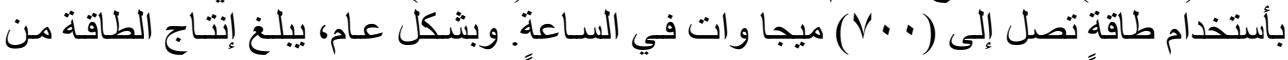

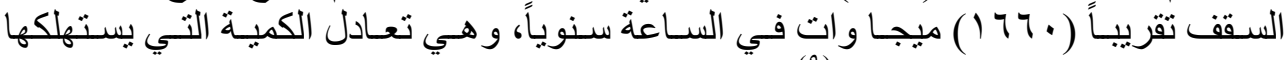

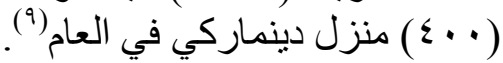




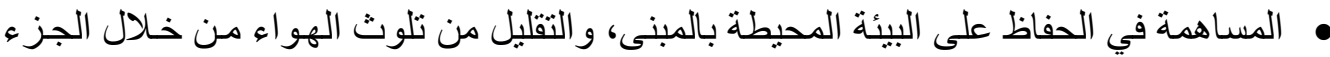

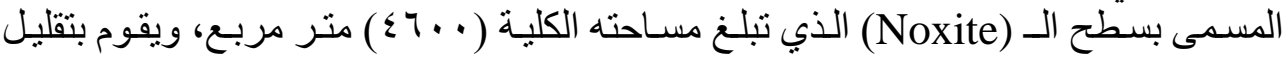

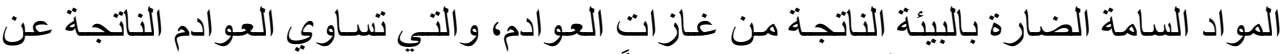

قيادة السيارة مسافة ( • ( ) ألف كيلو منر سنوياً.

r-r - • ا ثالثاً: المعالجة من منظور توظيف نسق الزيريسكيب (Xeriscape):

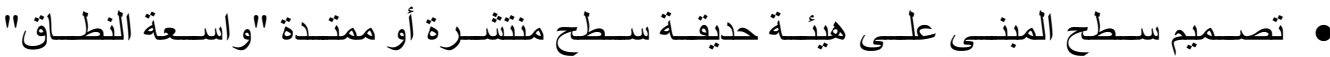
(Extensive Green Roof)

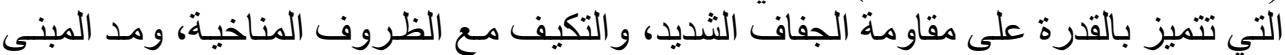
بالتدفئة عند إنخفاض درجات بات الحرات ارة، وتلطيف درجات الحر ارة المرتفعة.

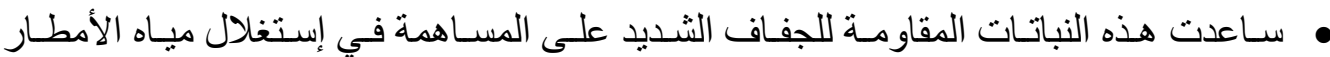

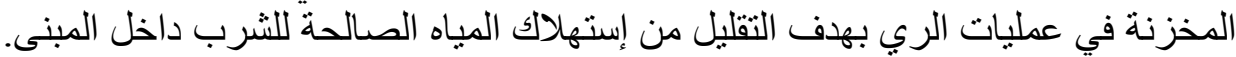

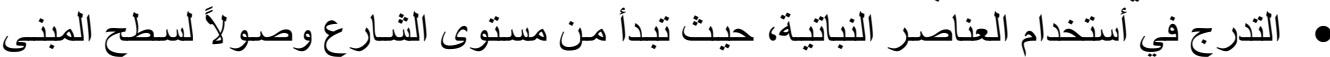

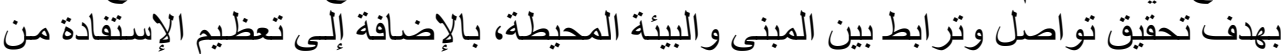
نسبة الخضرة الكبيرة أعلى سقف المبنى في التقليل من نسبة التلوث البيئي وتجميل البيئة.

r-r المثال الثالث: ناطحة سحاب كوهينور "Kohinoor Skyscraper":

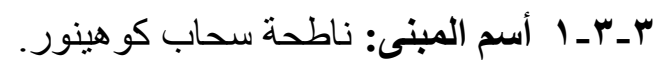

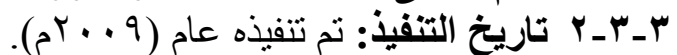

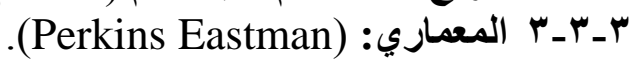

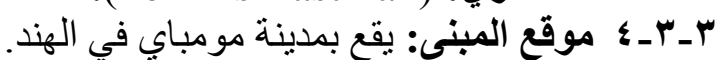

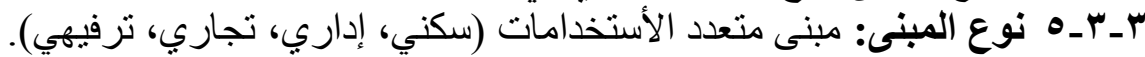

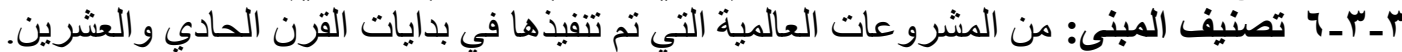

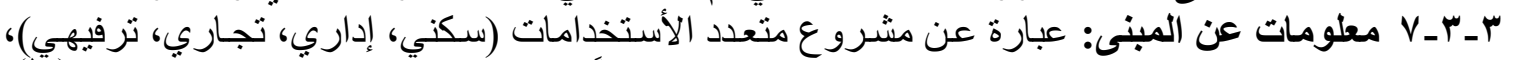

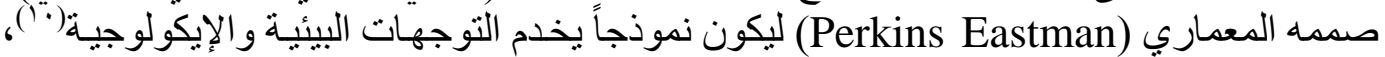

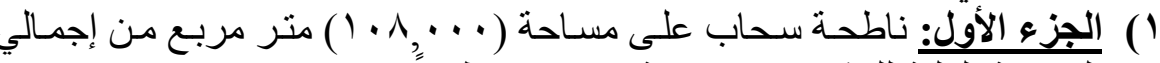
ويتكون من جزئين هما كالآتي:

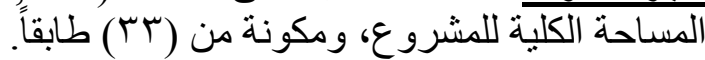

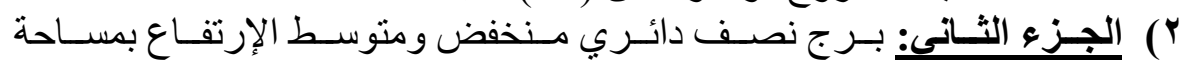

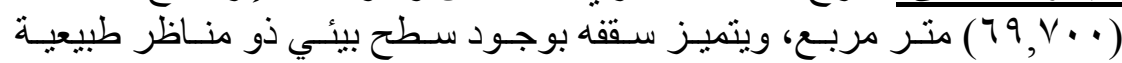

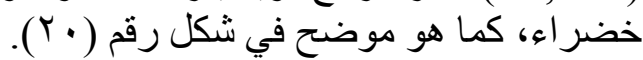

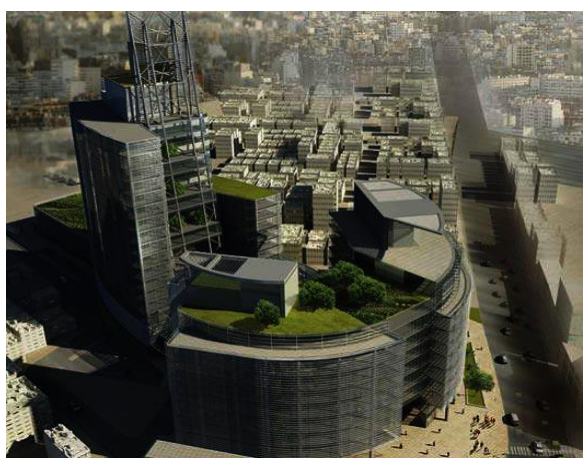

شكل رقم (· r) يوضح الموقع العام لناطحة سحاب كو هينور (Kohinoor Skyscraper)

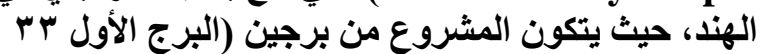

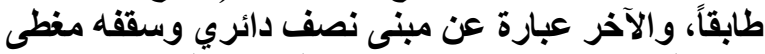

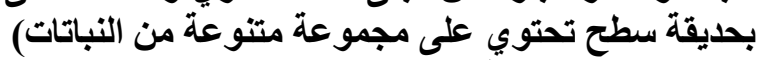

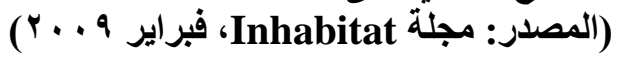


L N-r_r أولاً: المعالجة من منظور العناصر البيئية (المناخية) والمعمارية:

$$
\text { ا I-N-r-r }
$$

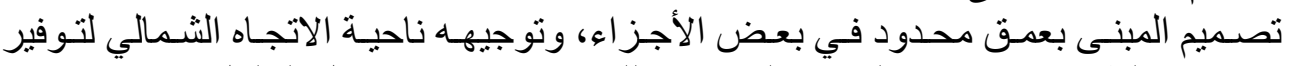

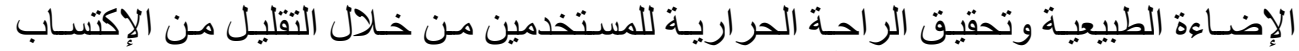

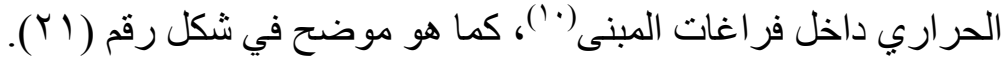

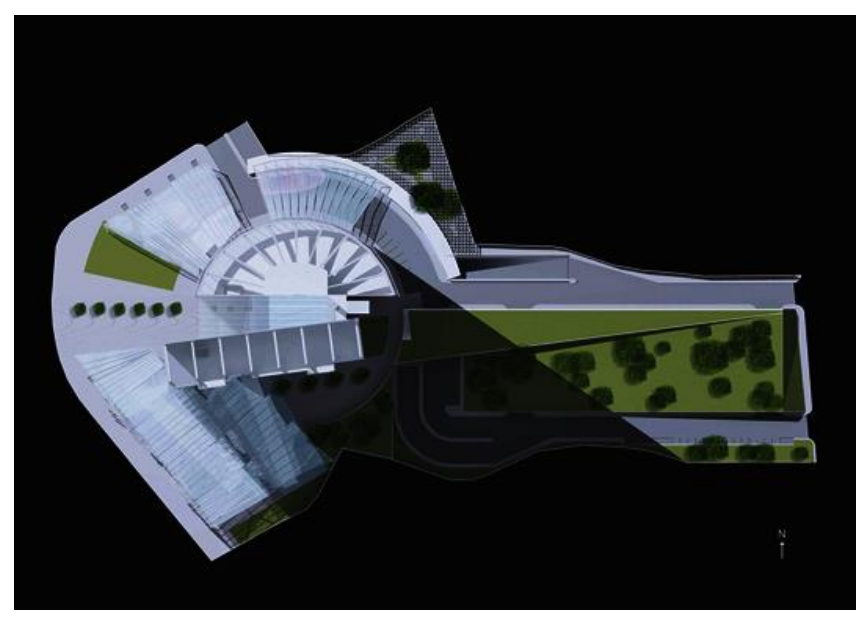

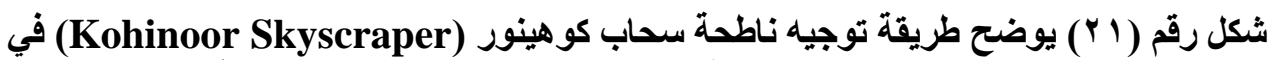

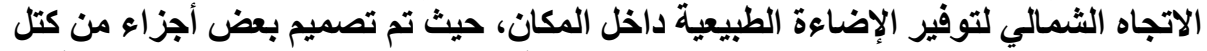

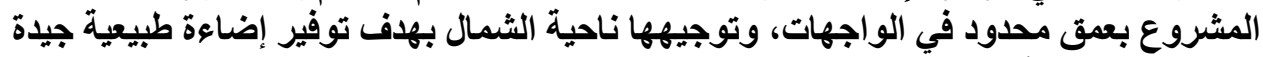

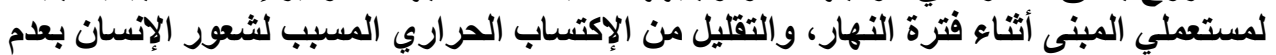

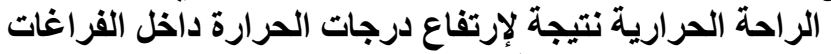

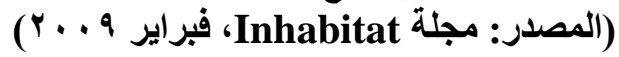

• توظيف عنصر الزجاج المزدوج الملون (Tinted double glazing) بالو اجهات الخارجية

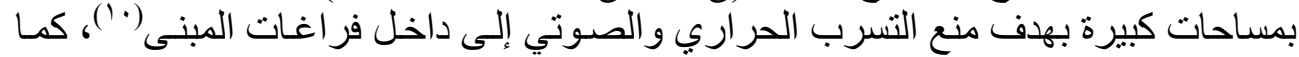

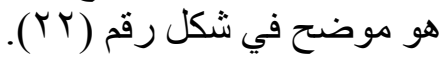

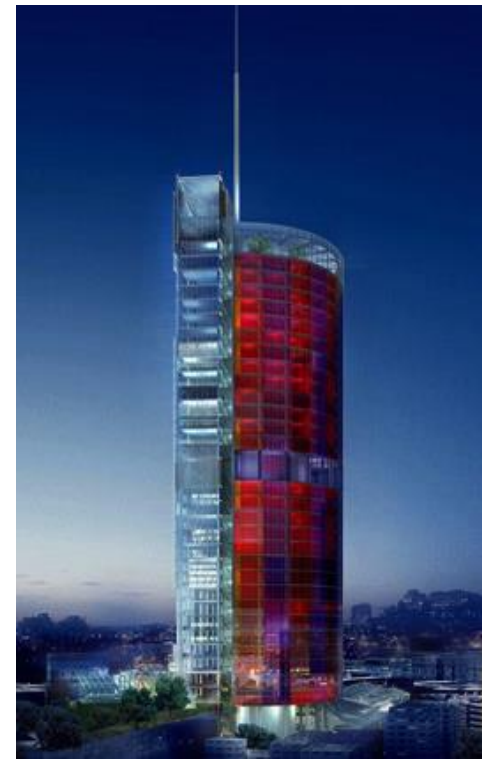

شكل رقم (Y Y ) يوضح طريقة توظيف المسطحات الزجاجية بالواجهات

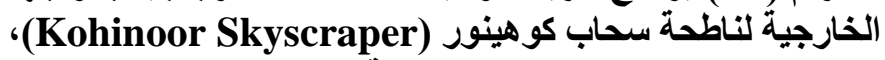

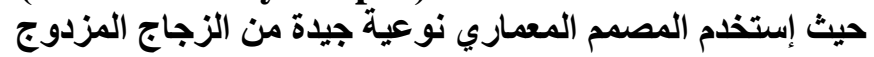

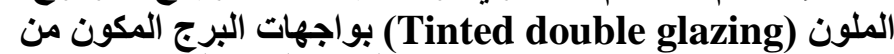

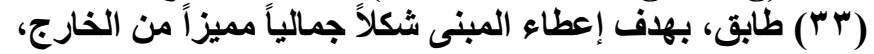

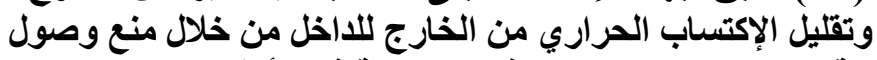

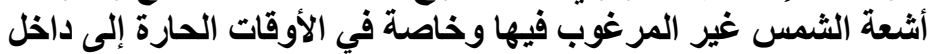

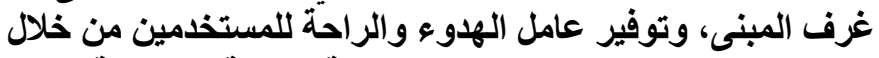
فصل المبنى عن مصادر الضوضير عامل المدوء الخارجية الناتجة من البيئة المحيطة URL: https://design-pedia.blogspot.com/ المصدر) 2009/02/again-green-design-architecture.html, accessed: December 20, 2020, 6:00 PM) 


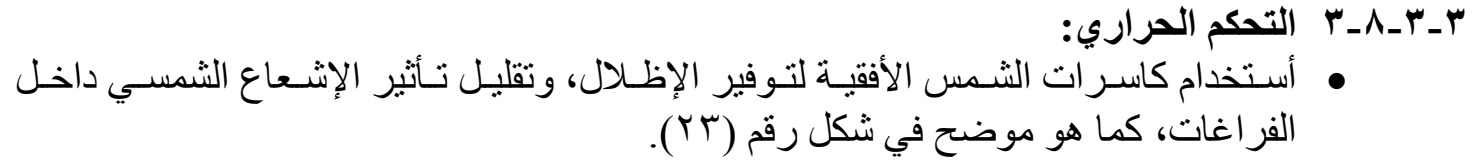

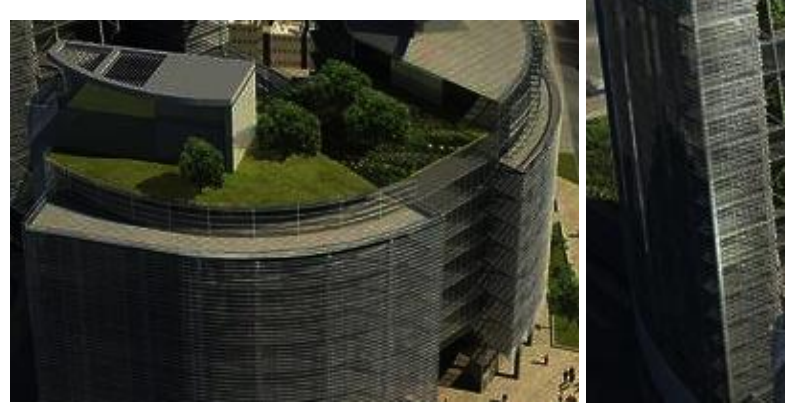

شكل رقم (r Y ) يوضح طريقة توظيف الكاسرات الثمسية بالو اجهات الخارجية لناطحة

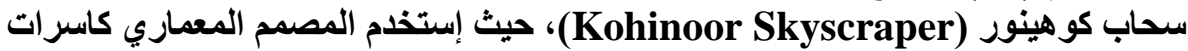

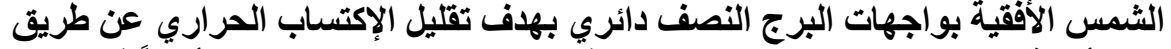

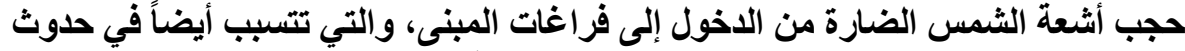
الوهج الثمسي الذي يؤثر على روئية مستعدلي المكان الثران

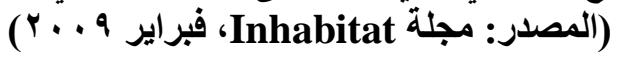

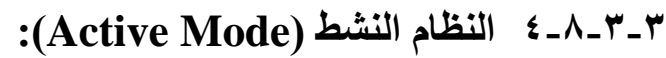

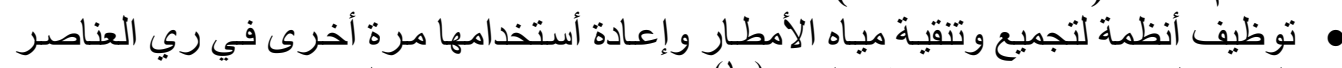

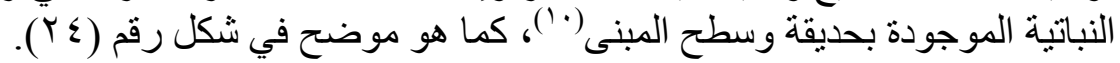

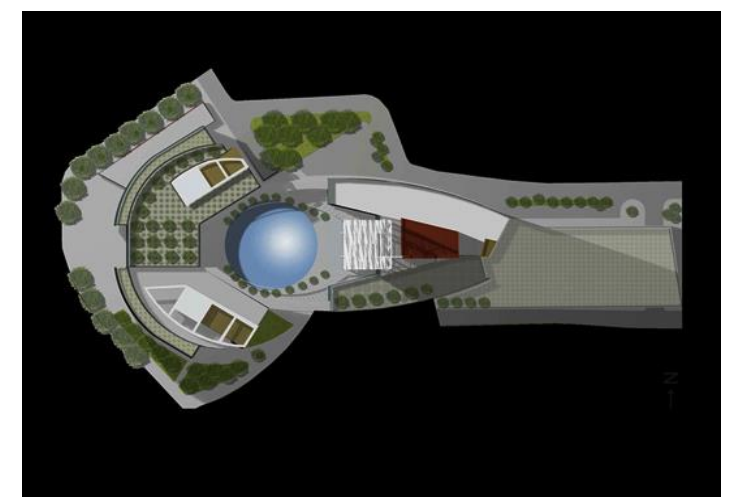

شكل رقم ( \& Y) يوضح كيفية ري العناصر النباتية بأسطح وحدائق ناطحة سحاب كوهينور (Kohinoor Skyscraper)

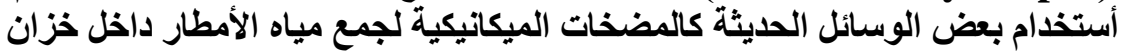

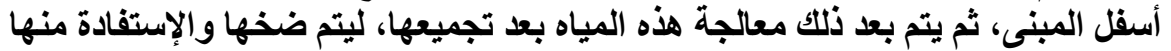

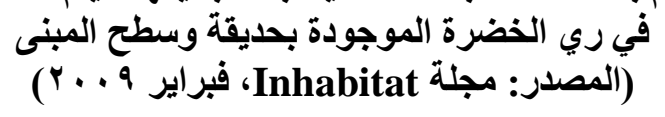

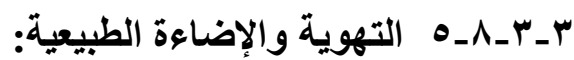

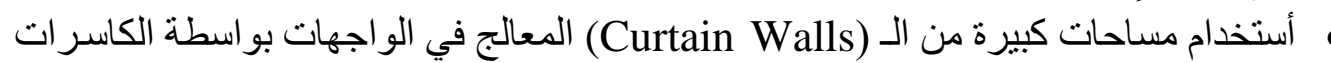
الثمسية لتوفير الإضاءة الطبيعية داخل غرف المن المبنى.

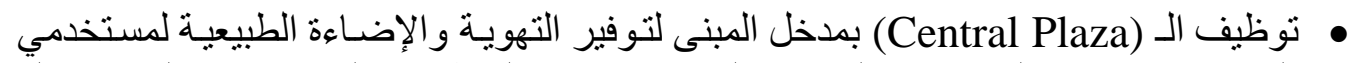

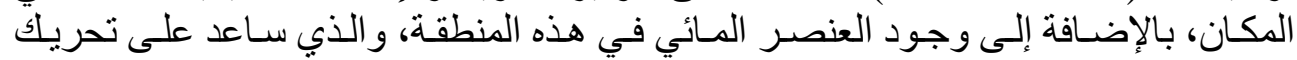


الهو اء بين أجز اء المبنى مما أدى أيضاً إلى توفير التهويـة الطبيعيـة داخل الفراغات(·(')، كمـا

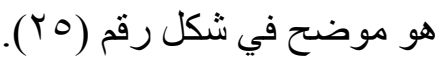

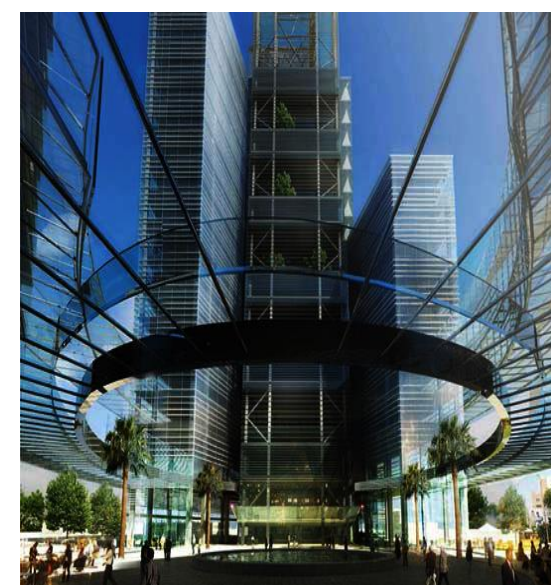

شكل رقم († Y) يوضح طريقة توظيف الـ (Central Plaza) بمدخل ناطحة سحاب كو هينور (Kohinoor Skyscraper)

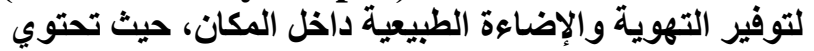

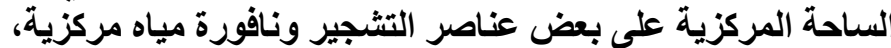

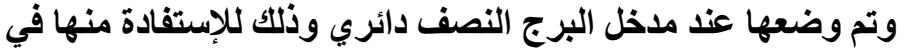

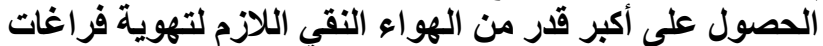

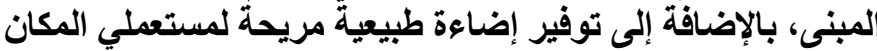

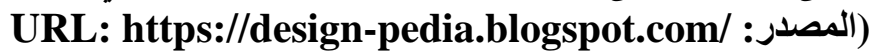
2009/02/again-green-design-architecture.html, accessed: December 20, 2020, 11:00 PM)

 • الإستفادة من الطاقة الثمسية في تسخين المياه داخل المبنى.

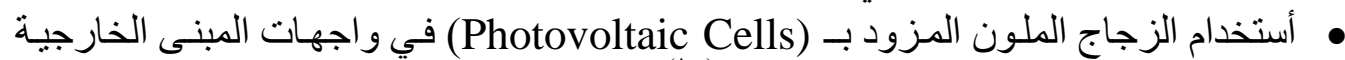

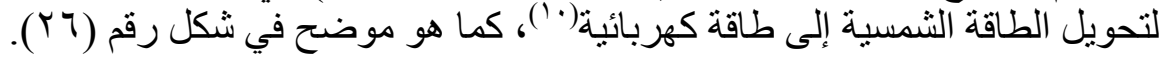

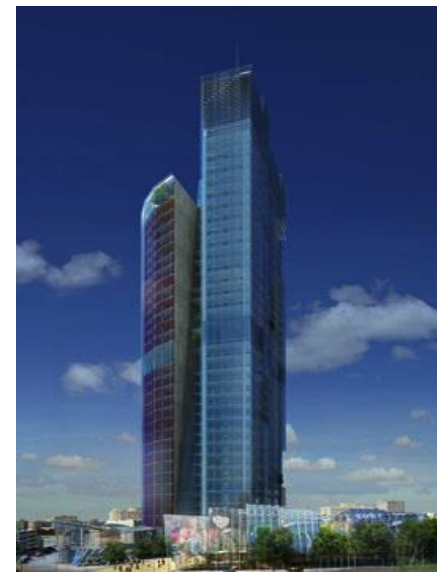

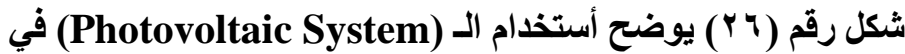
ناطحة سحاب كوهينور (Kohinoor Skyscraper) لتوليد الطاقة الكهربائية، حيث إستخدم المصمم المعماري الزجاج المبات الملون المزود

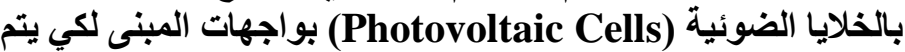

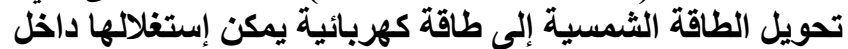

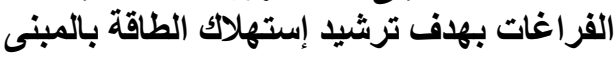

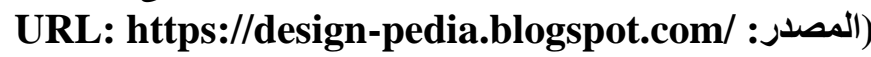
2009/02/again-green-design-architecture.html, accessed: December 22, 2020, 7:00 AM)

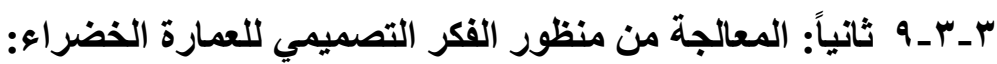

• توفير عنصـر الإظلال، وحمايـة الفراغـات الداخليـة للمبنى من الإشـعاع الثمسيسي بأستخدام

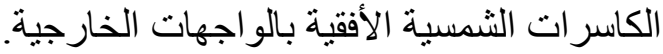

• توفير الر احة الحرارية داخل الفر اغات من خلال أستخدام مساحات كبيرة ذات التهات نوعية محددة

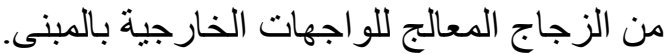
• توفير التهوية الطبيعية بالمبنى من خلال التوجيه التهاجيه الجيد لتقليل إستهلاك أجهزة التكييف داخل الفر اغات بهدف ترشيد إستهلاك الطاقة. • توظيف الـ (Curtain Walls) بالواجهات بهـف توفير الرؤية الخارجية للمحيط العمر اني،

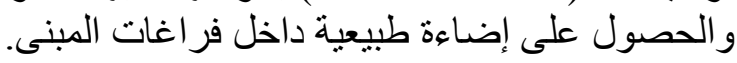

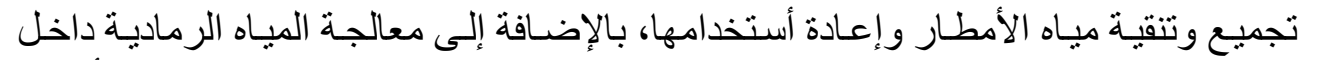

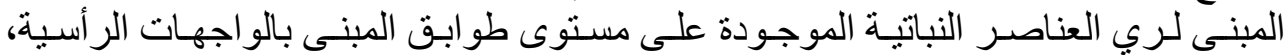

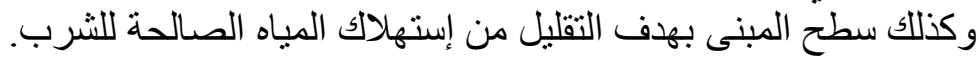




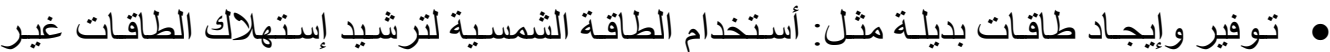

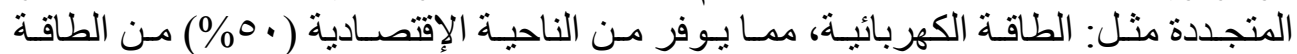
المستهلكة في الإضاءة الصناعية داخل المبنى.

r-r- • ا ثالثاً: المعالجة من منظور توظيف نست الزيريسكيب (Xeriscape):

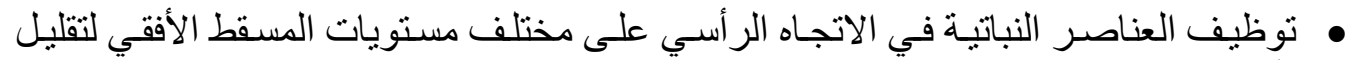
تأثثير الإشعاع الثمسي على الفراغات الداخلية للمبنى، كما هو موضح في شكل رقم (YV)

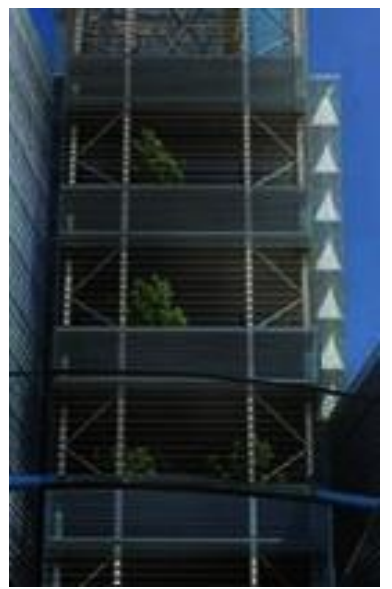

شكل رقم (YV) يوضح أستخدام العناصر النباتية على مستوى طوابق ) ئق

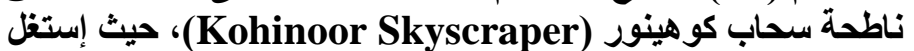
المصمم المعماري التراسات الخارجية المطلة على الساحة المركزية (Central Plaza)

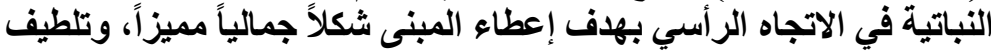

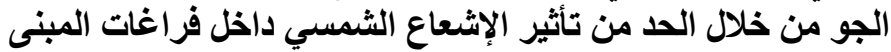

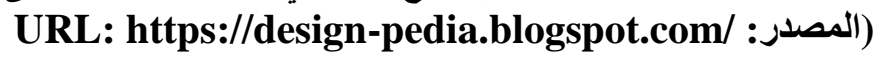
2009/02/again-green-design-architecture.html, accessed: December 23, 2020, 6:00 PM)

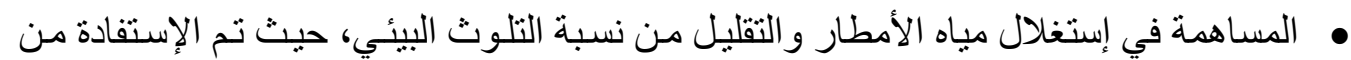

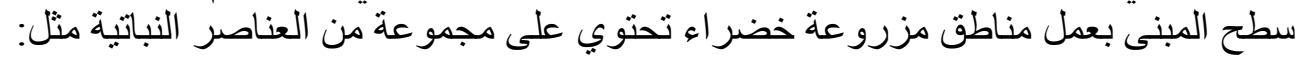

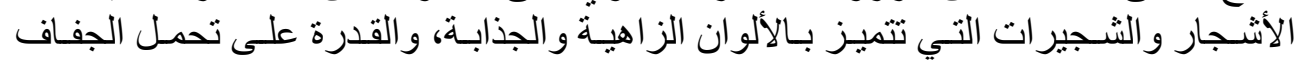

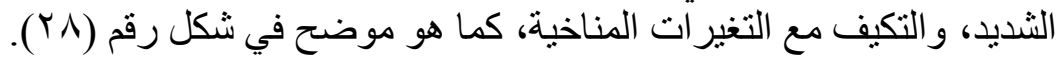

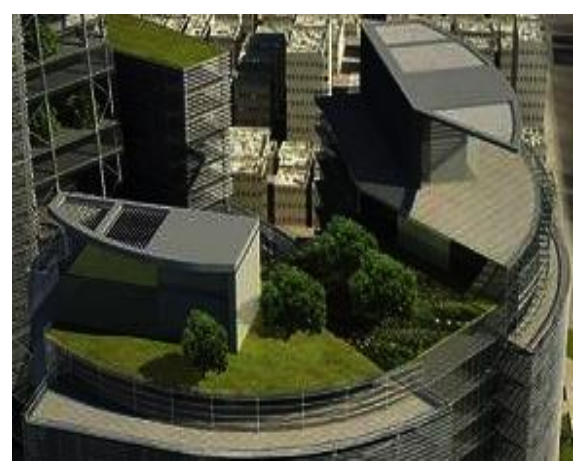

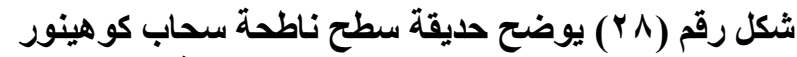
(Kohinoor Skyscraper)

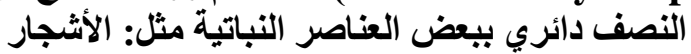

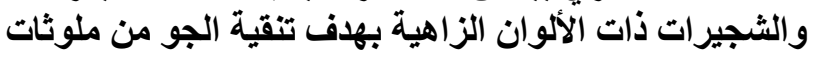

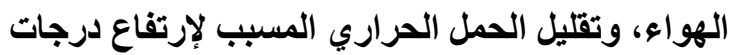

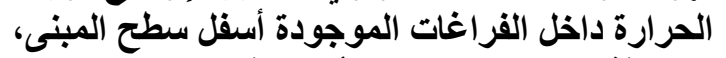

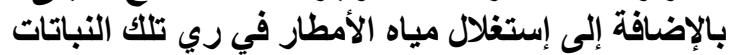

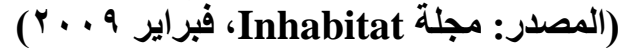

"' "Green Towers in the Park" المثنال الرابع: الأبراج الخضراء

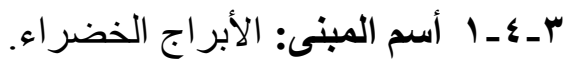

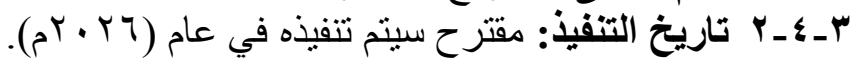

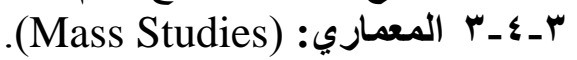

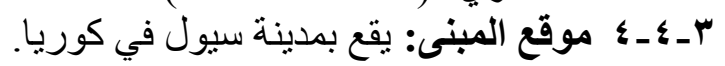

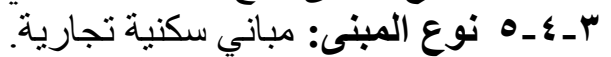

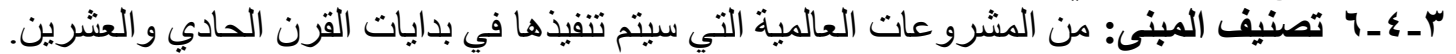

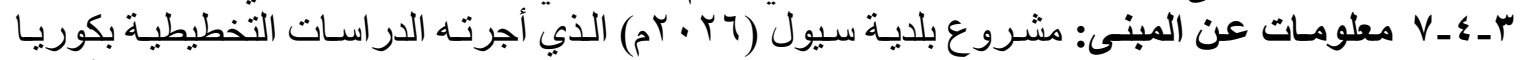

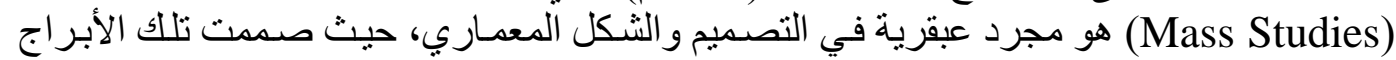

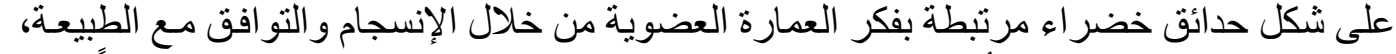

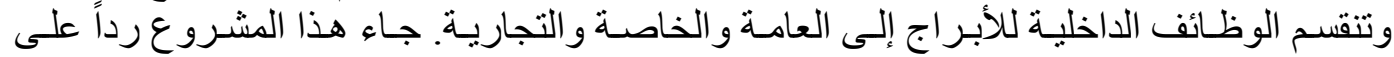




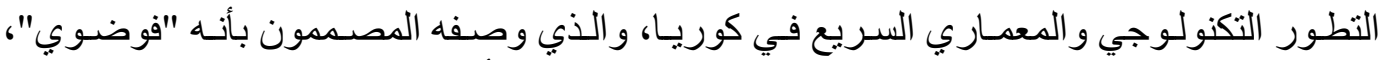

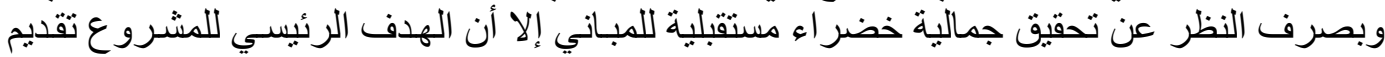

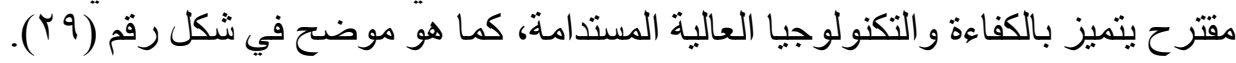

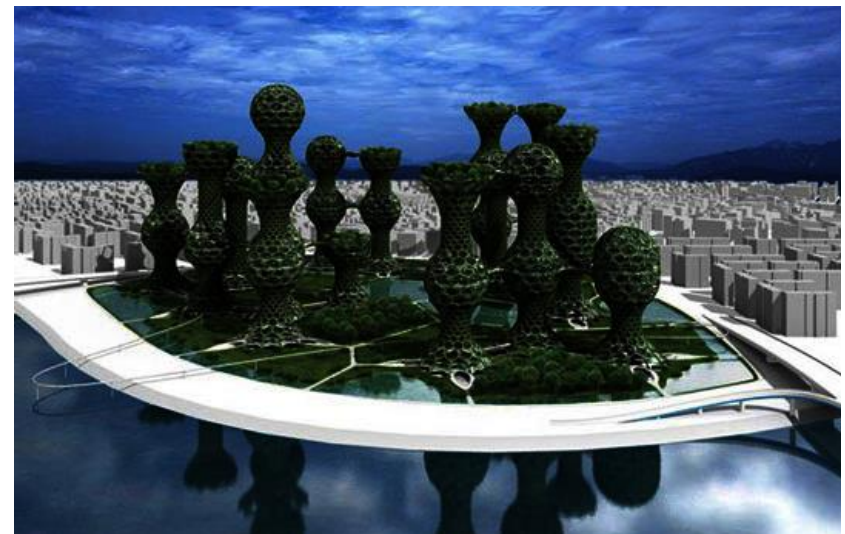

شكل رقم (q Y ) يوضح الموقع العام للأبراج الخضراء (Green Towers in the Park)

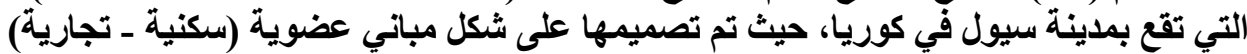

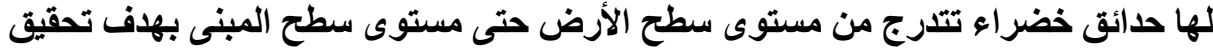

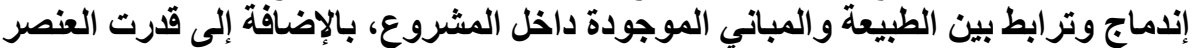

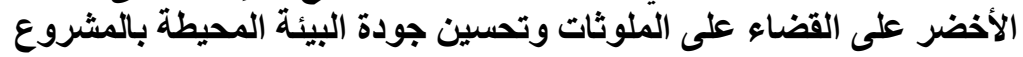

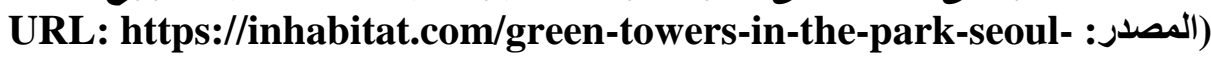
commune-2026/, accessed: December 25, 2020, 10:00 AM)

r- _ــ أولاً: المعالجة من منظور العناصر البيئية (المناخية) والمعمارية:

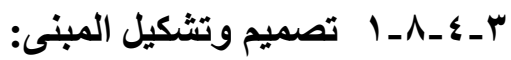

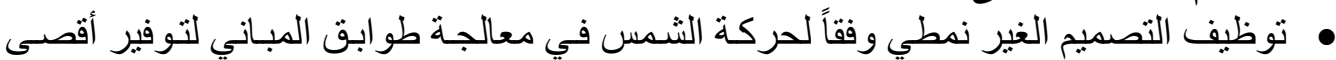

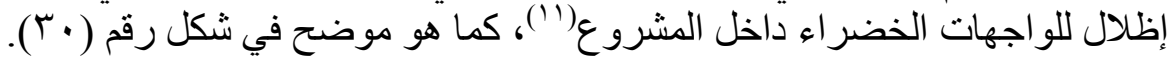

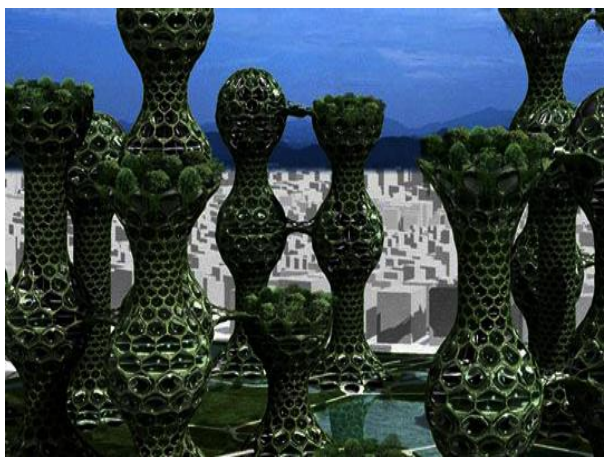

شكل رقم ( • ب) يوضح طريقة توظيف التصميم الغير نمطي بالأبراج الخضر (ن) (Green Towers in the Park)

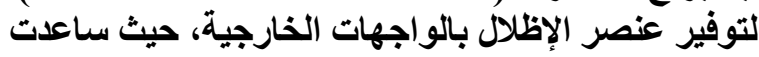

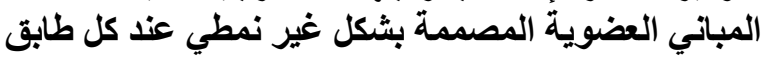

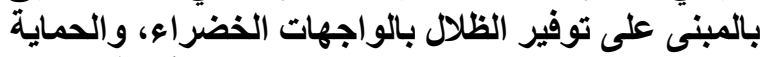
من الوهج الثمسي من خلال التقليل من حدة أثعة الثمات الثمس الثماية

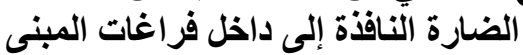

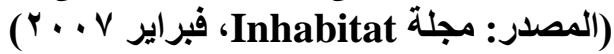

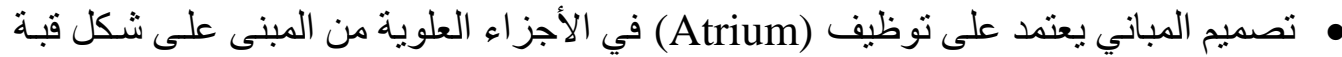

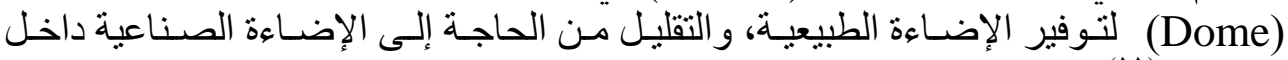
الفر اغات(' (')، كما هو موضح في شكل رقم (1) (ب). 


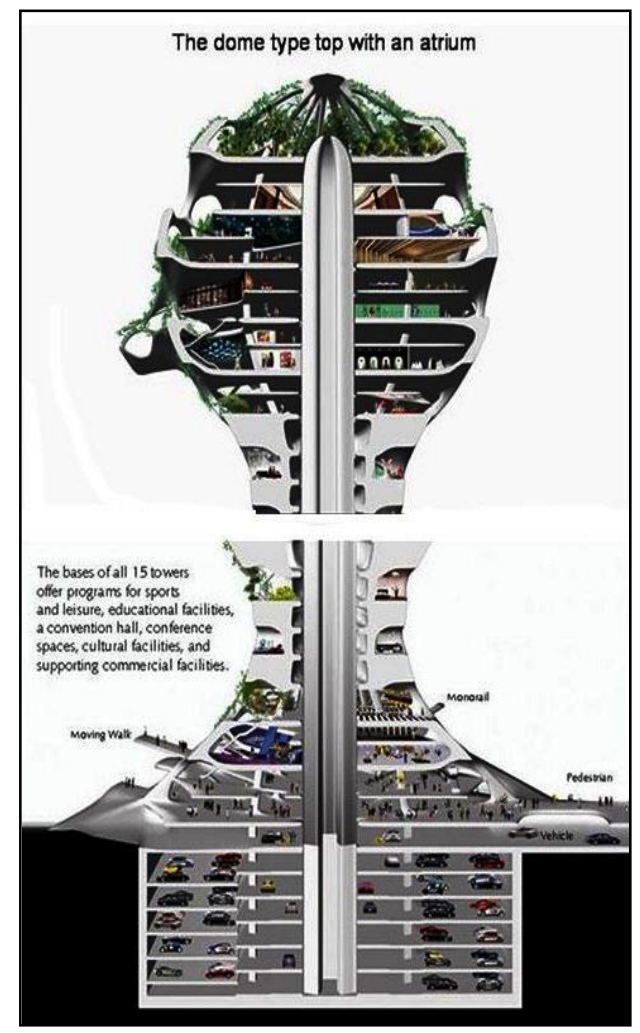

شكل رقم ( آس) يوضح طريقة توظيف الـ (Atrium)

بالأبراج الخضر (تواء (Green Towers in the Park)

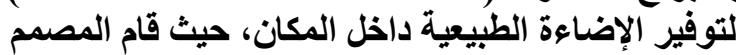

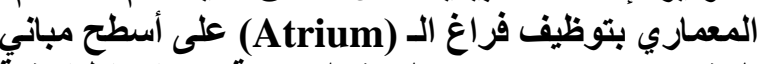

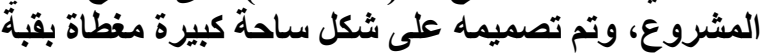

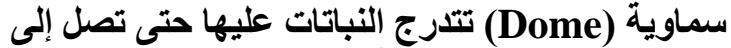

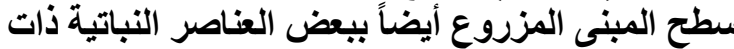

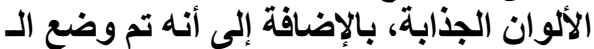

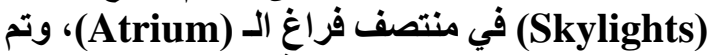
توصيلها بيعض الفراغات الداخلية من خلال الـ (Core)

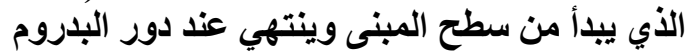

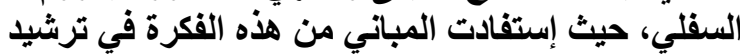

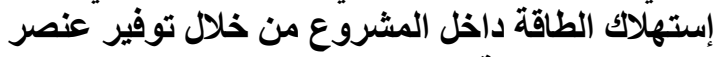

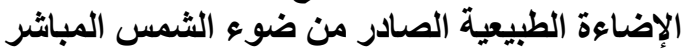

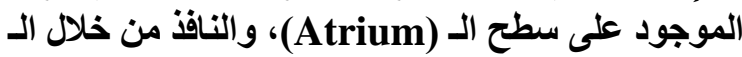
(اللى داخل فراغات المبنى (Skylights)

URL: https://i.pinimg.com/ المصند) originals/a4/06/fc/a406fc61a27bdca7 dc0e9bc394a1a375.jpg, accessed: December 25, 2020, 11:00 AM)

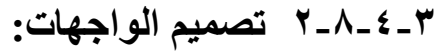

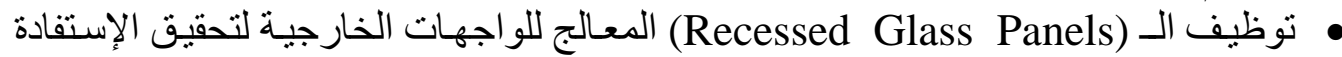

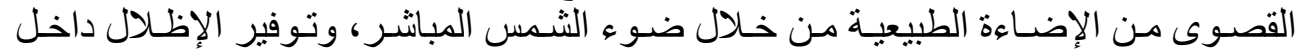

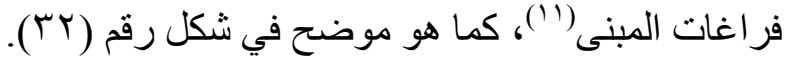

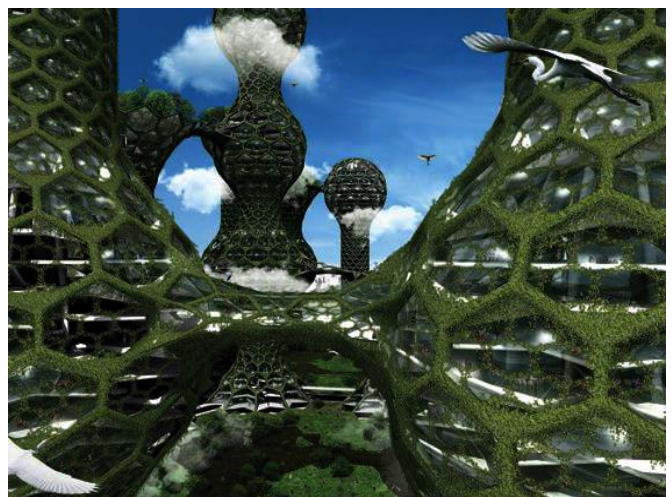

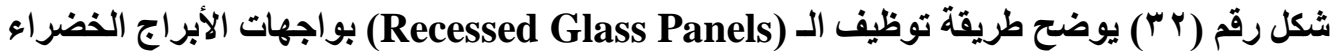
لتوفير الإظلال داخل غرف المبنى، حيث إستخدم المصمم المعماري (Green Towers in the Park)

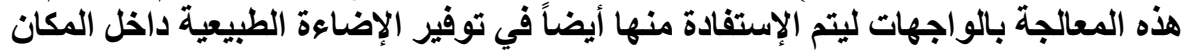

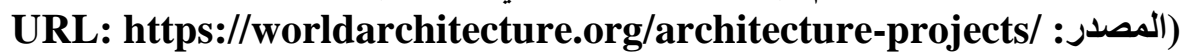
cmfv/seoul-commune-2026-rethinking-towers-in-the-park--project -pages.html, accessed: December 27, 2020, 9:00 AM) 


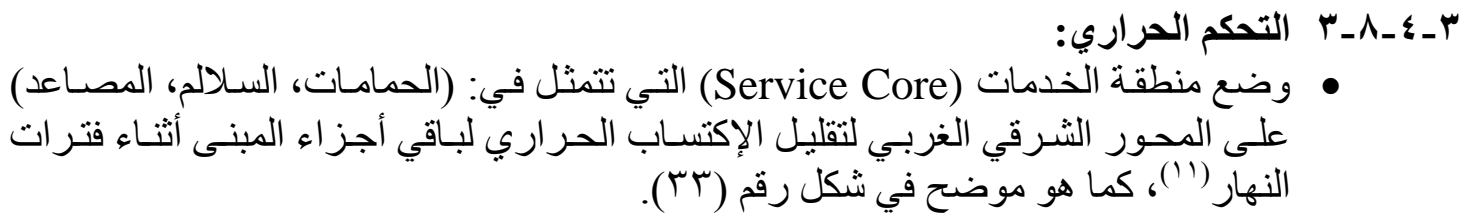

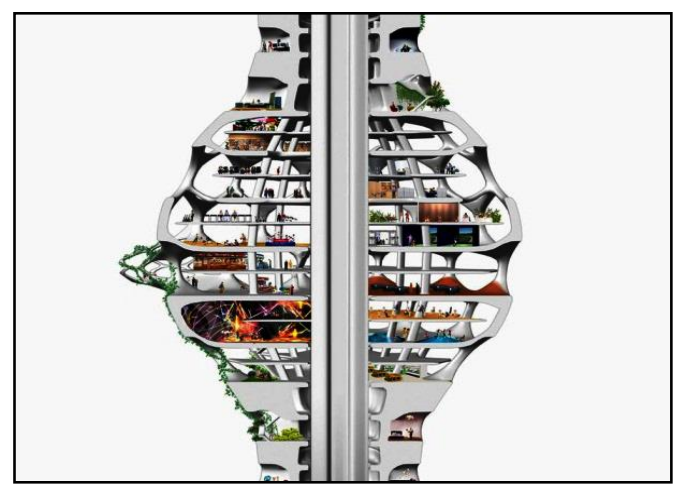

شكل رقم (TrT) يوضح طريقة توظيف منطقة الخدمات (Service Core) داخل الأبراج

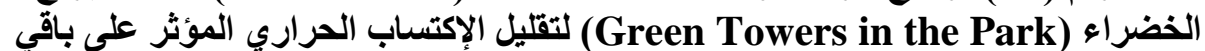

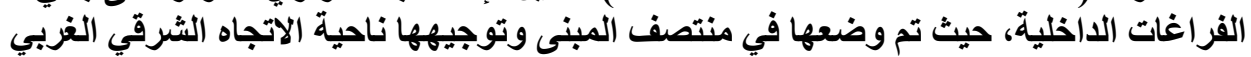

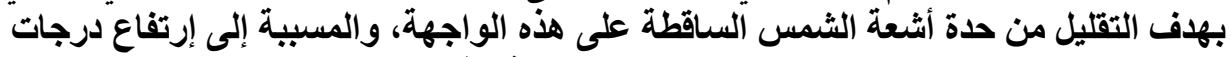

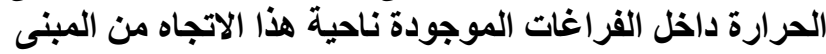

URL: https://geekologie.com/2008/03/seoul-commune-2026- :المصندة) looks-uh-be.php, accessed: December 27, 2020, 5:00 PM)

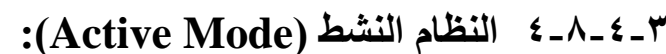

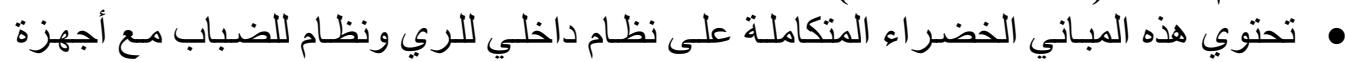

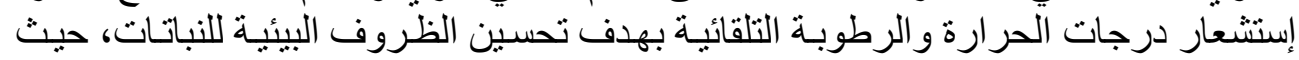

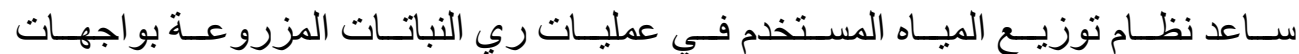
على تخفيض نسبة (•recessed Glass Panels)

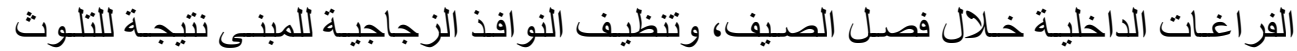

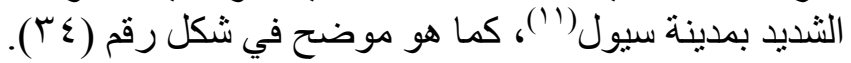

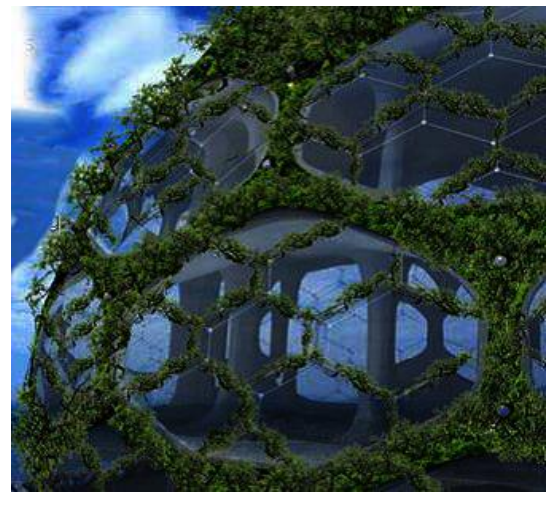

شكل رقم (ع ب) يوضح فكرة الإستفادة من نظام توزيع مياه الأمطار

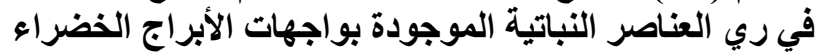
(Green Towers in the Park) المعماري فكرة الثكل السداسي الموجودة بـواجهات الـ الـ (Recessed Glass Panels) الخارجي بيعض النباتات الخضر اءو وذلك للإستفادة منها في تبريد

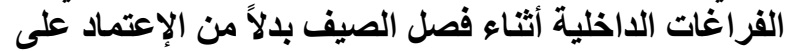

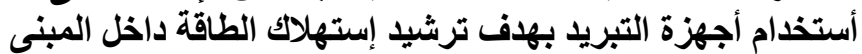

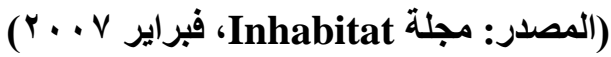

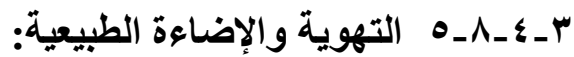

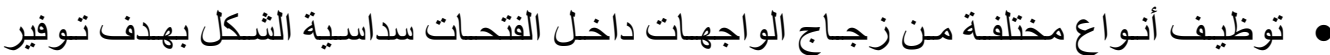

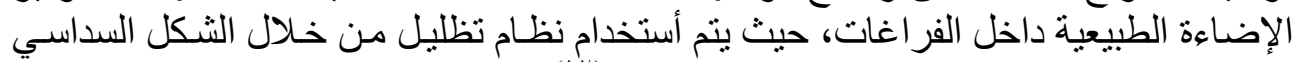

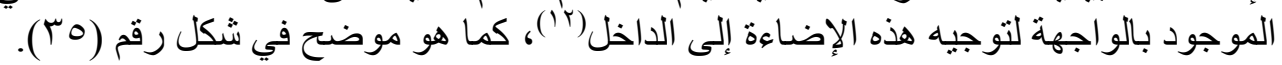




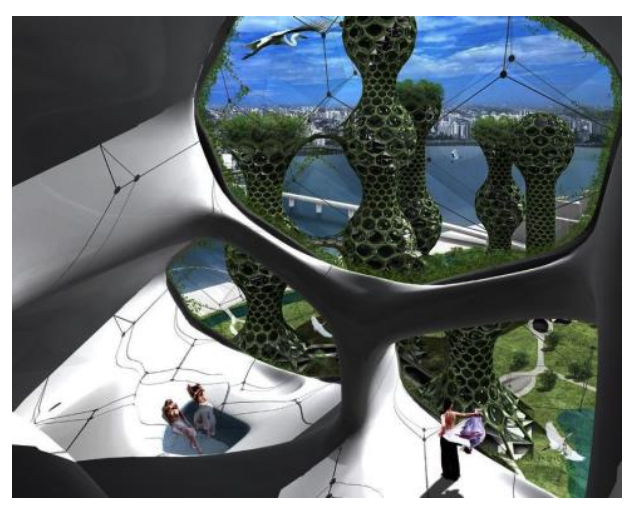

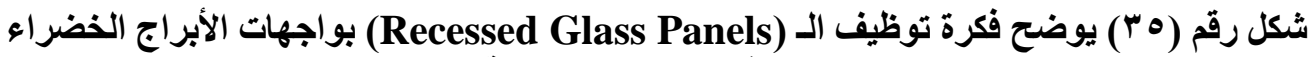

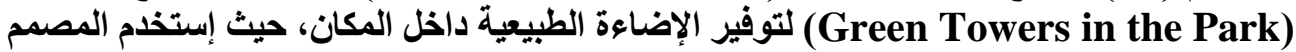

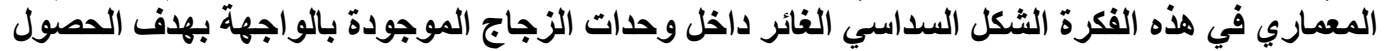

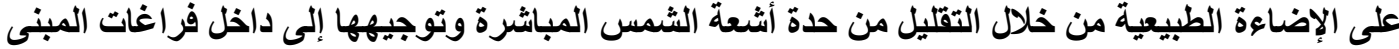

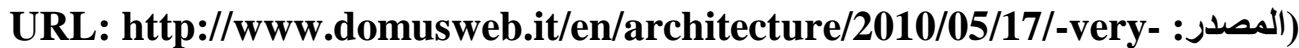
green-utopias.html, accessed: December 29, 2020, 8:00 AM)

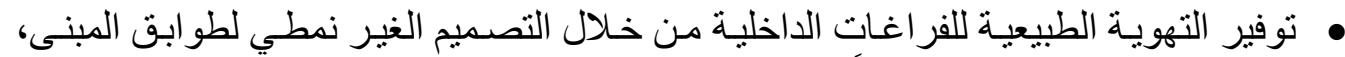

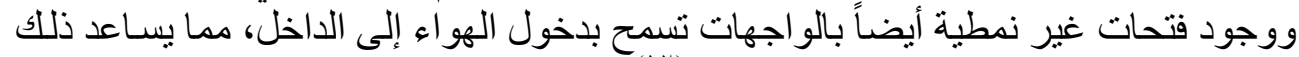

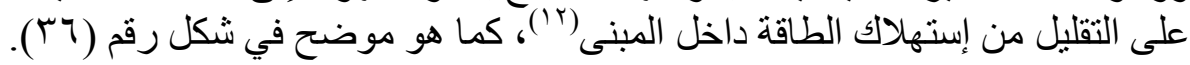

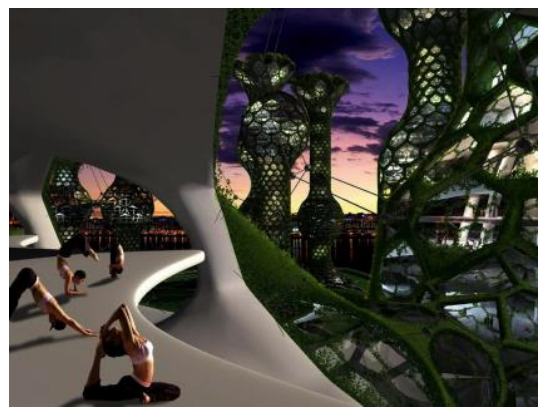

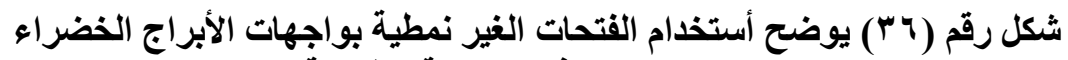

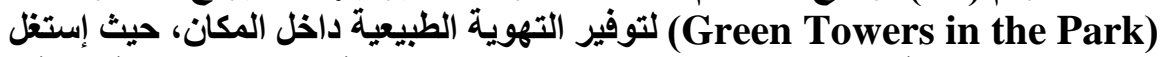

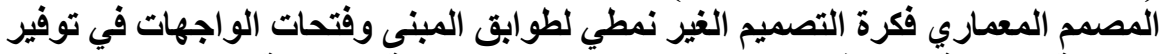

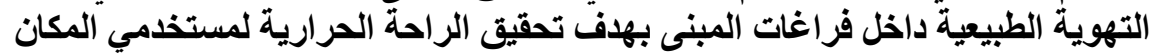

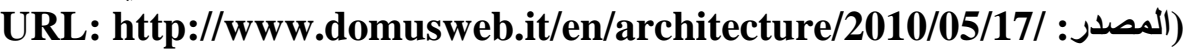
-very-green-utopias.html, accessed: December 29, 2020, 5:00 PM)

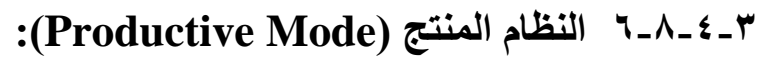

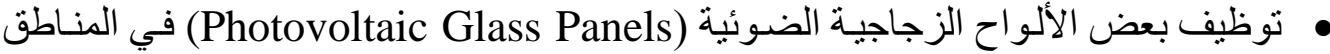

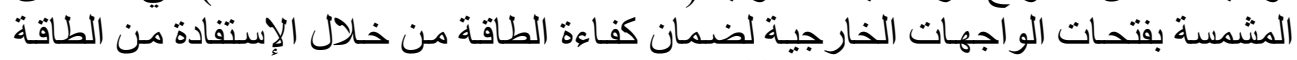

الشمسية وتحويلها إلى طاقة كهربائية(1).

r- ـ ـ ـ ثانياً: المعالجة من منظور الفكر التصميمي للعمارة الخضر اء:

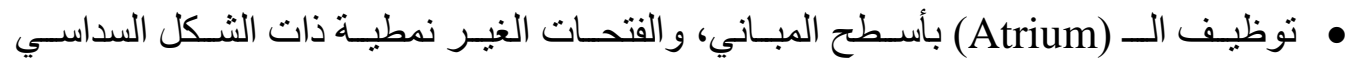
بالو اجهات الخارجية لتوفير التهوية والإضـاءة الطبيعية بالمبنى.

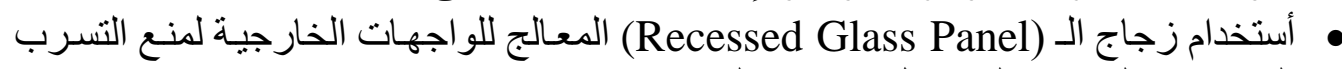
الحر اري و الصوتي إلى داخل فر اغات المبنى. 
• أستخدام الـ (Photovoltaic Panels) بو اجهات المباني لتوفير الطاقة المستهلكة من خلال إستغلال الطاقة الشمسية وتحويلها إلى طاقة كهربائية.

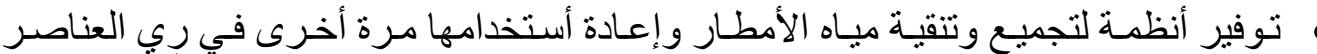

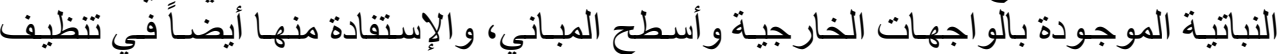

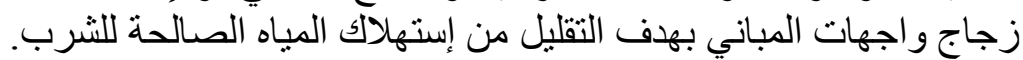

r- ـ - • أثاً: المعالجة من منظور توظيف نسق الزيريسكيب (Xeriscape):

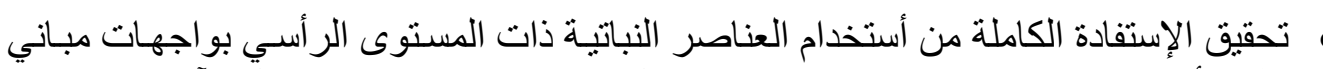

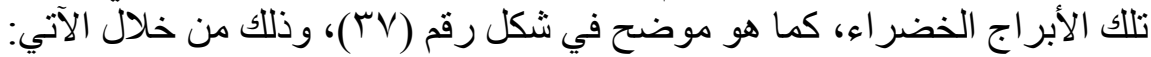

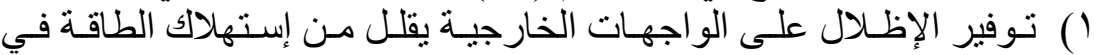

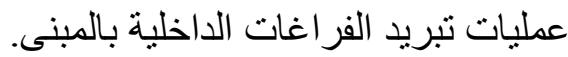

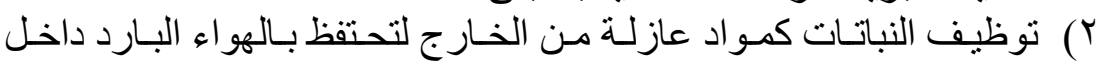

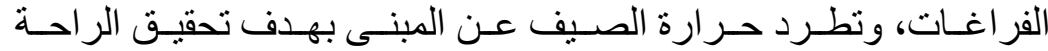
الحر ارية للمستخدمين داخل المكردان.

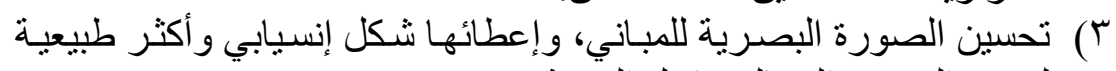
لتوفير العنصر الجمالي داخل المدينة. ع) التقليل من الآثار السلبية للتلوث البيئي، و الذي تعانية منه مدينة سيول.

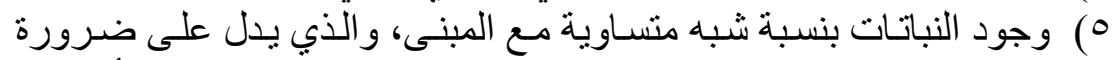

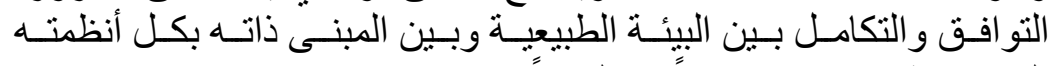

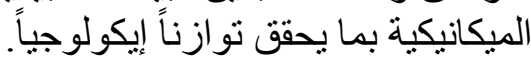

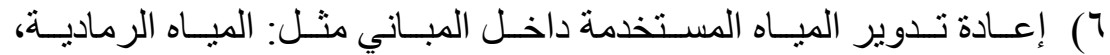

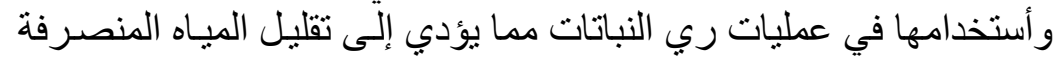
في شبكات الصرف بالمدينة.

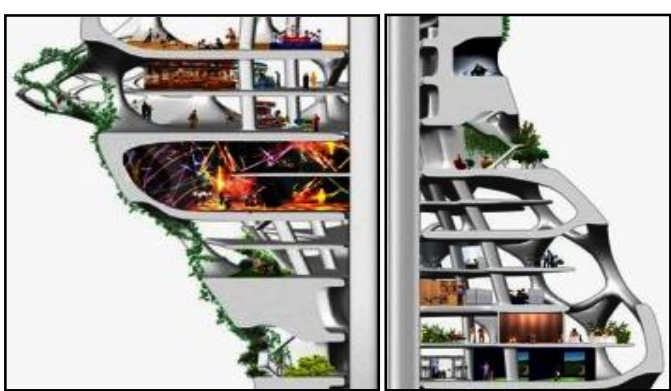

شكل رقم (rv) يوضح فكرة تدرج العناصر النباتية بواجهات الأبراج الخضراء

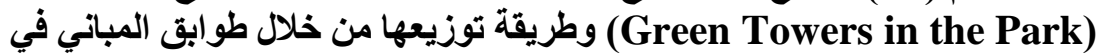

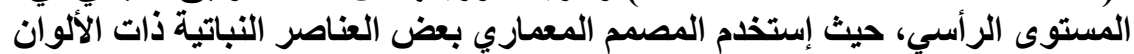

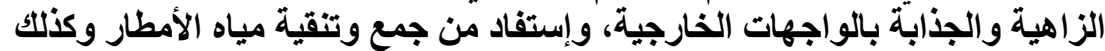

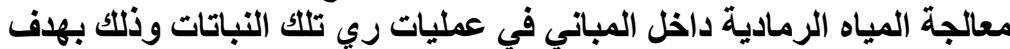

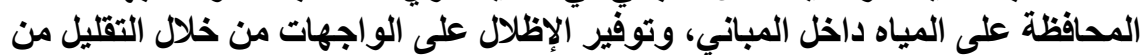

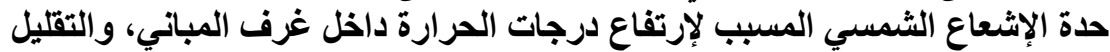

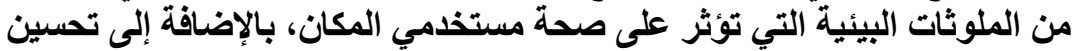

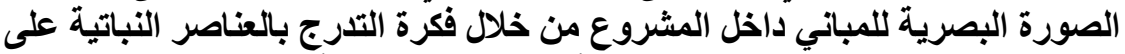

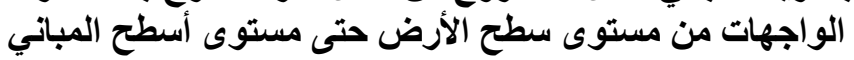

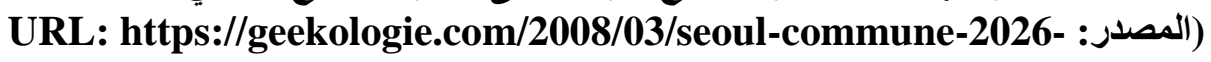
looks-uh-be.php, accessed: December 31, 2020, 9:00 AM) 


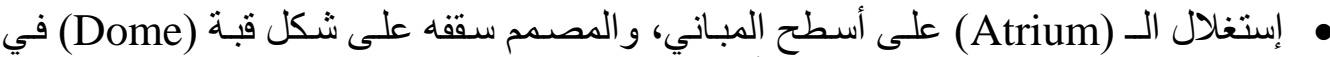

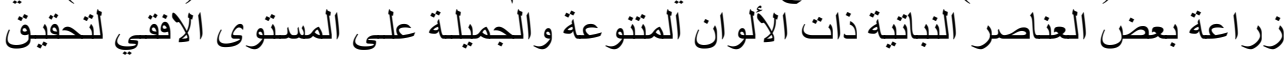

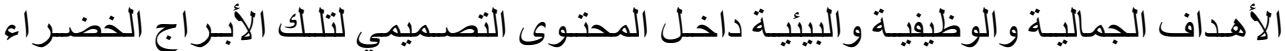

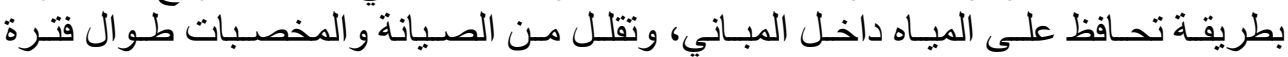

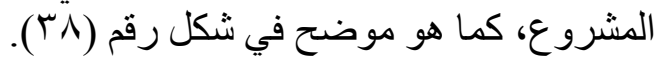

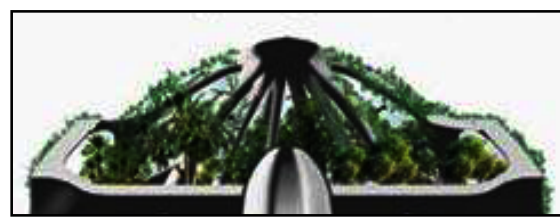

شكل رقم (^^) يوضح فكرة إستغلال الـ (Atrium) في زراعة بعض النباتات على أسطح الأبراج

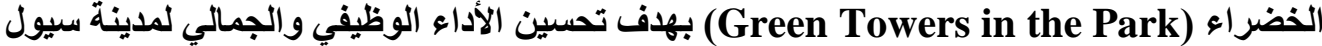

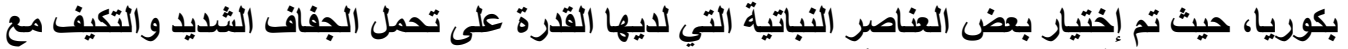

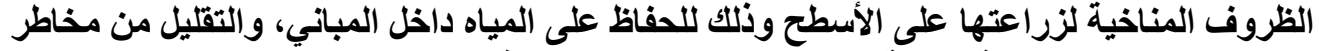

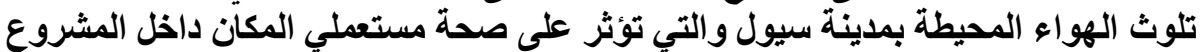

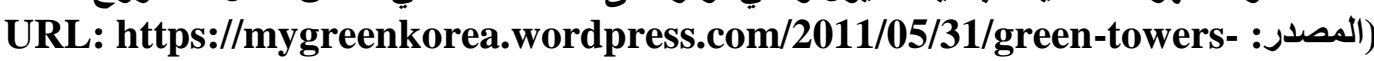

in-the-park-seoul-commune-2026/, accessed: December 31, 2020, 2:00 PM)

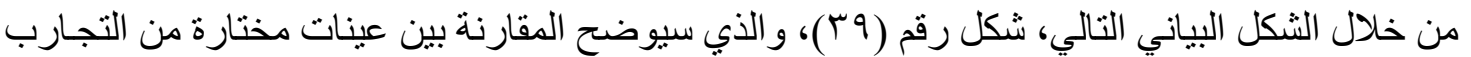

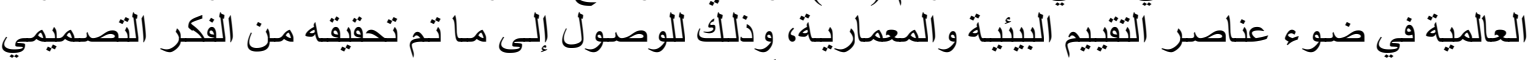

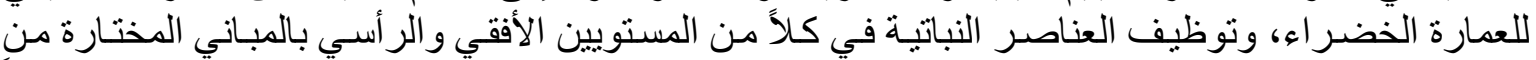

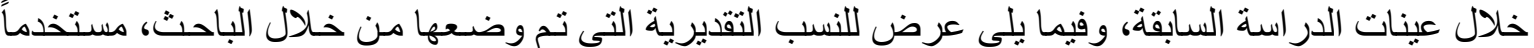

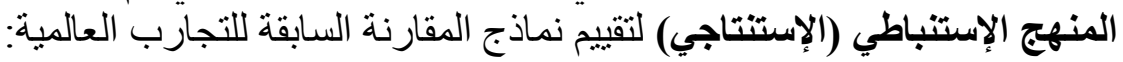

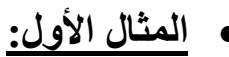

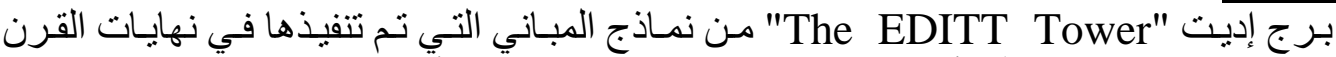

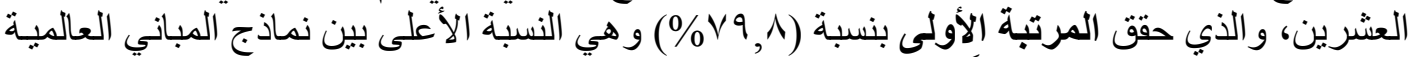
ل اللعينات المختارة بالدر اسة سابقاً.

مبنى بوسطن فيوجن "Boston Fusion" من نماذج المباني التي تم تنفيذها مع بدايات القرن

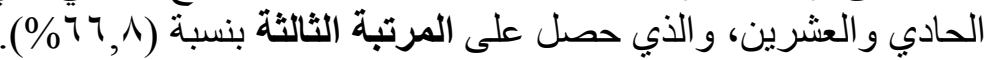

• المثال الثالث:

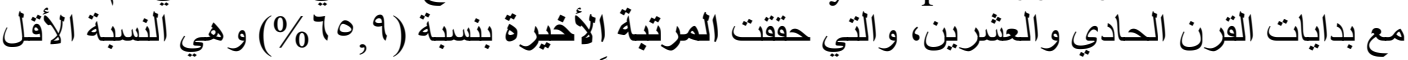
بين نماذج المباني العالمية للعينات المختارة بالدر اسة سابقاً.

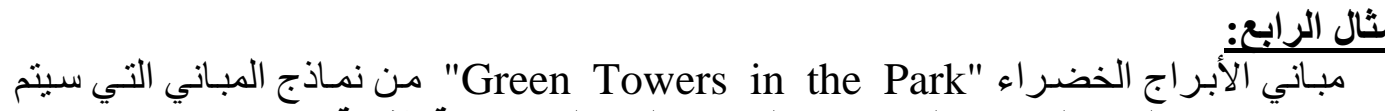

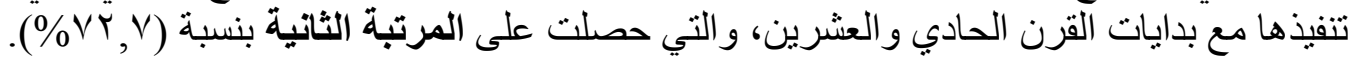




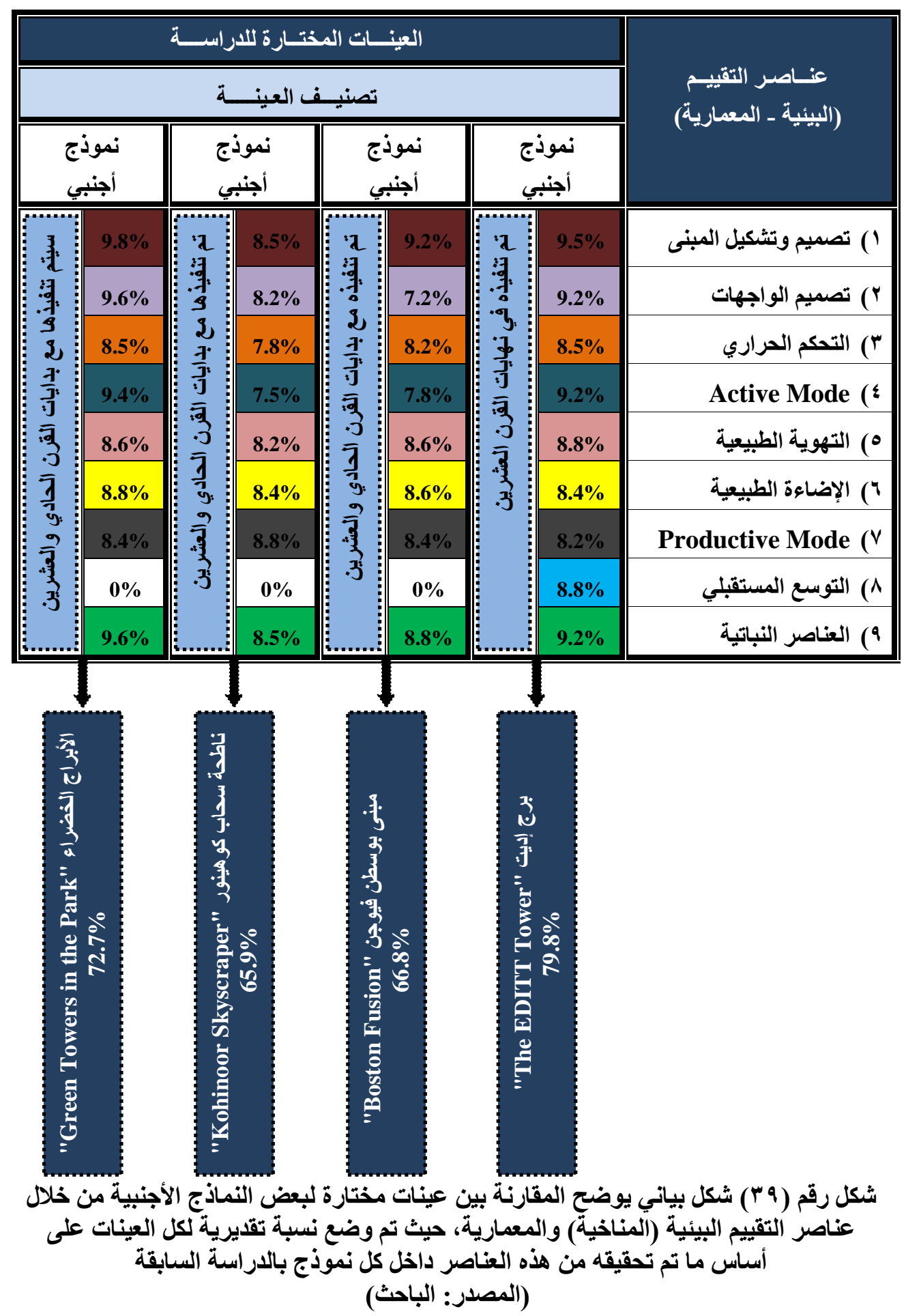

$$
\text { عـ - التتائج والتوصيات: }
$$

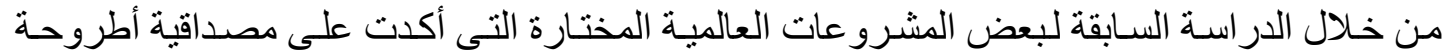

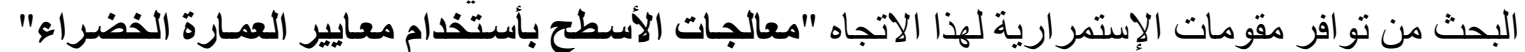

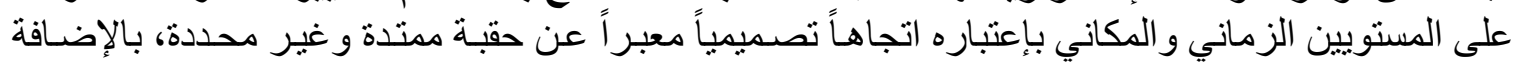

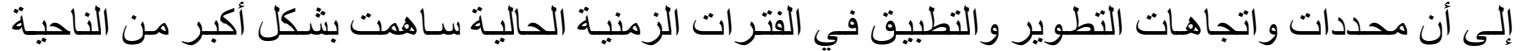


الإقتصادية في ترشيد إستهلاك الطاقات داخل المباني مقارنة بالفترات الزمنية الماضية وحققت أيضـاً الر احـة

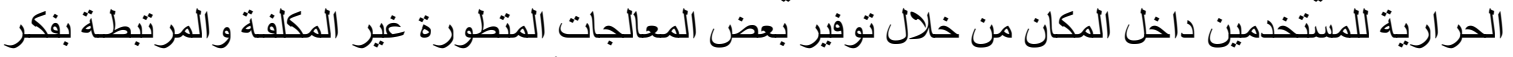

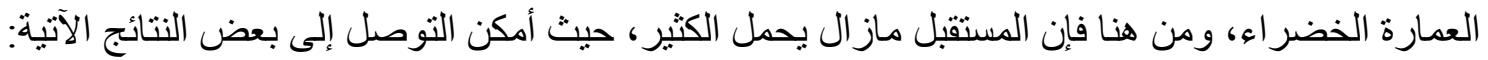

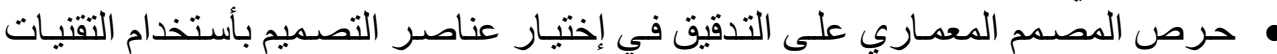

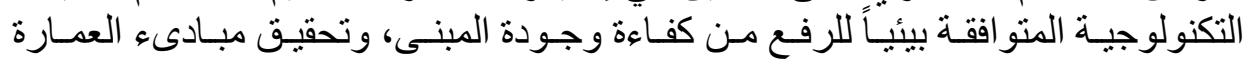

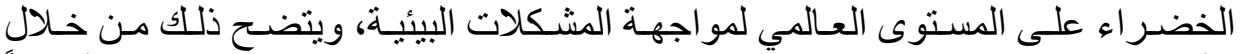

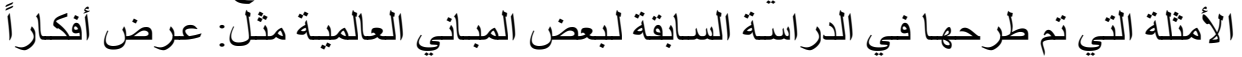

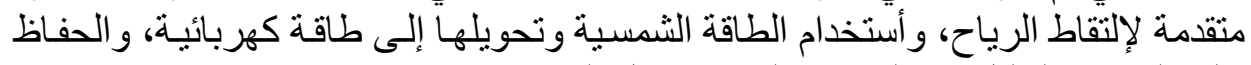

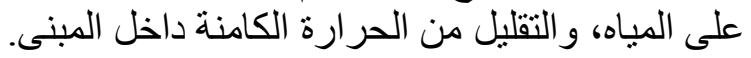

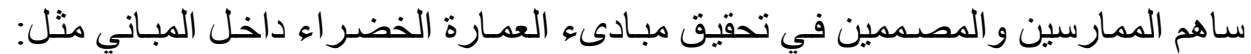

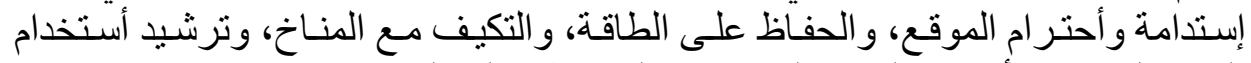

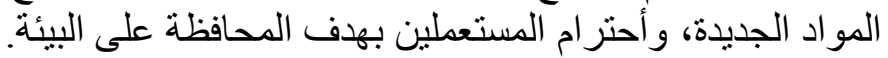

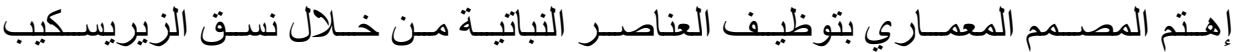

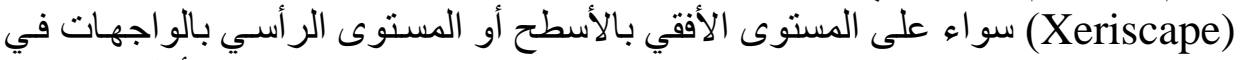

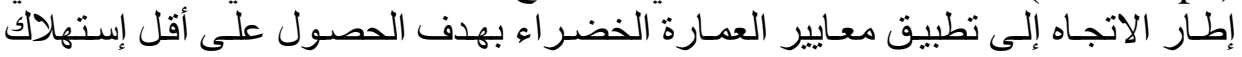

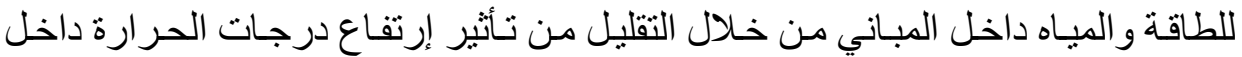

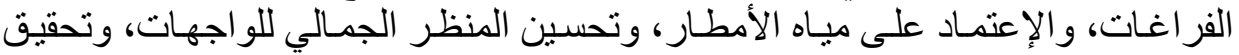
توازن ملحوظ بين البيئة المبنية والبيئة الطبيعية.

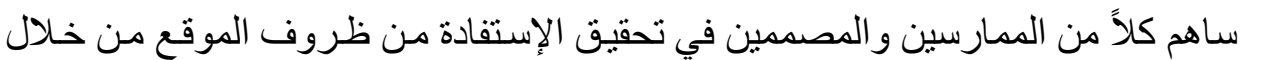

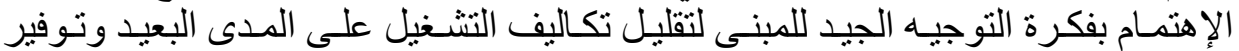

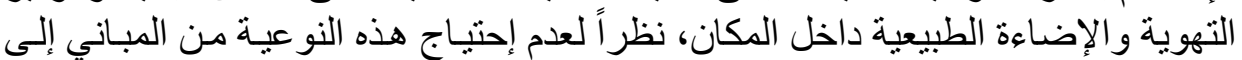

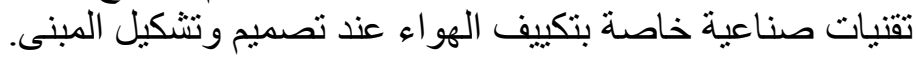

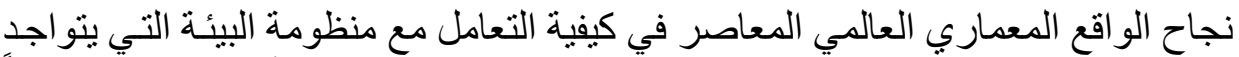

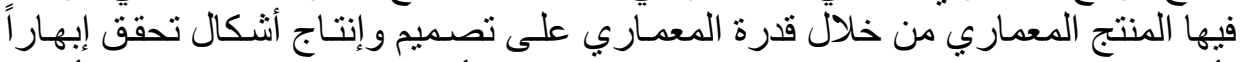

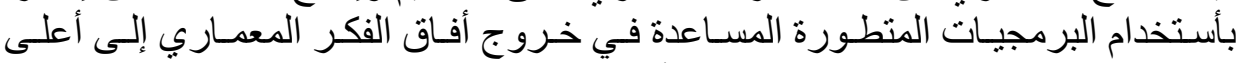

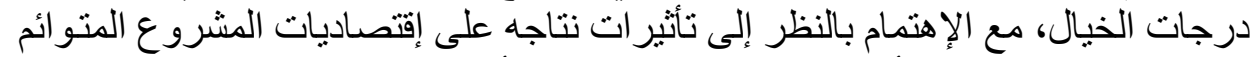

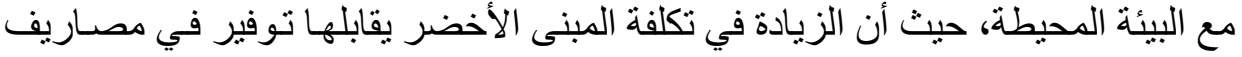
تشغيل وصيانة المبنى على المدى الطوّيل.

r المسئولون في مختلف الإدارات والهيئات البيئية:

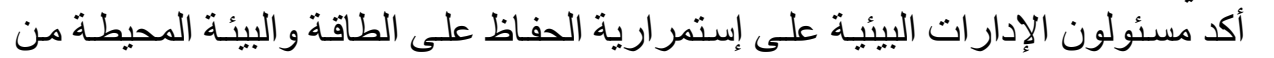

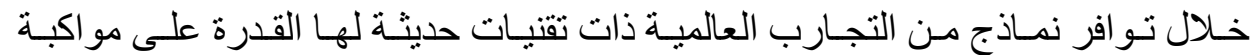

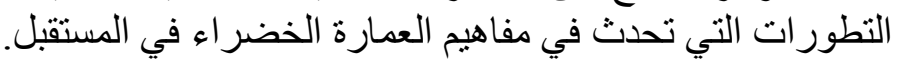

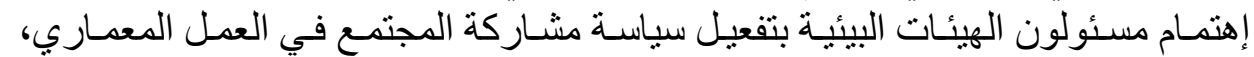

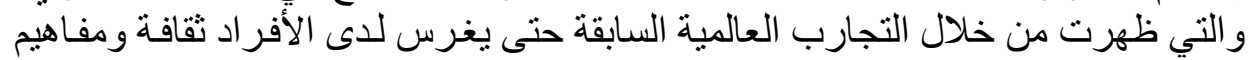

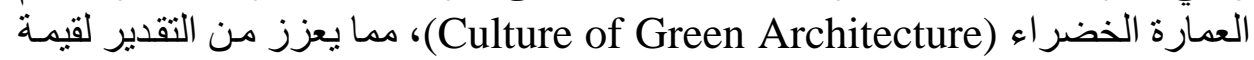

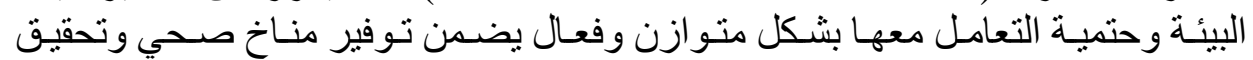
الكفاءة الأمثل للمبنى من النواحي البيئية و المناخية.

r) المؤسسات والمراكز البحثية:

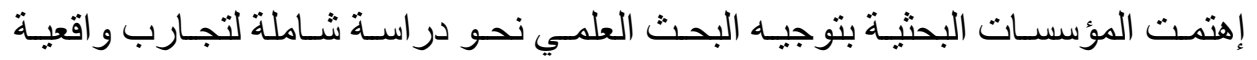

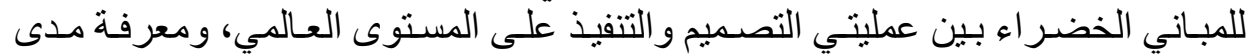

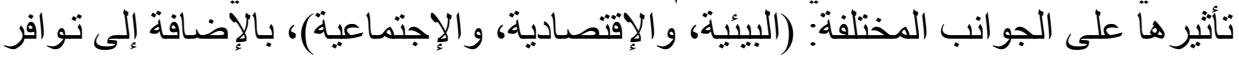




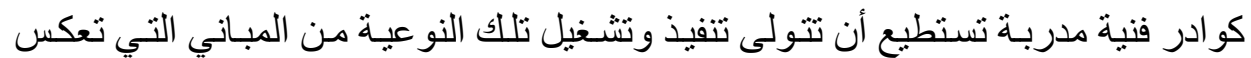

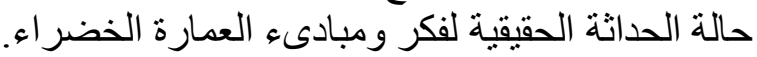

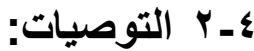

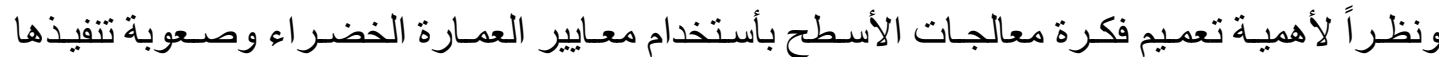

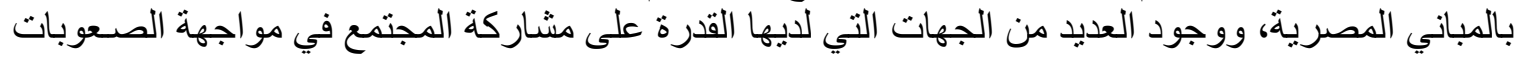

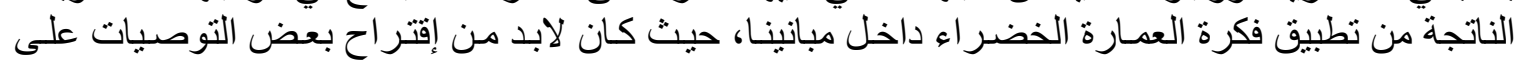

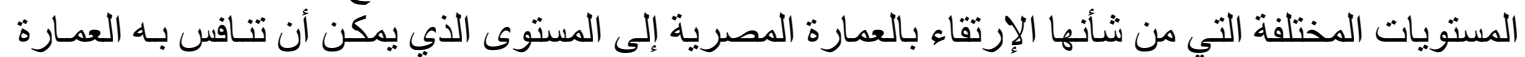

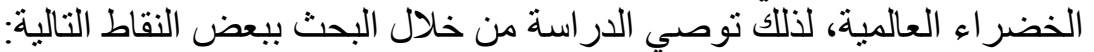

\section{(1) على مستوى المؤسسات التعليمية والأكاديمية:}

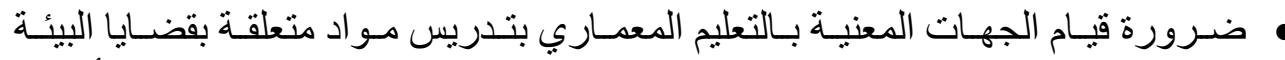

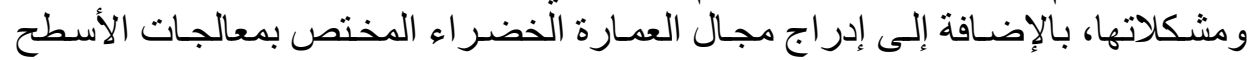

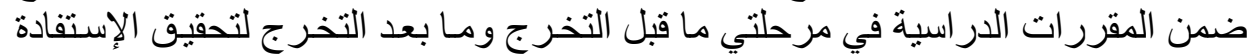

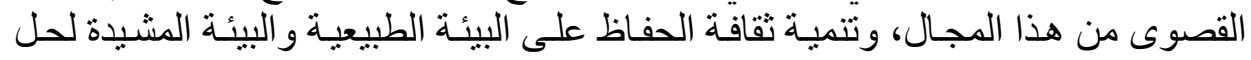

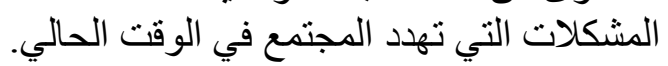

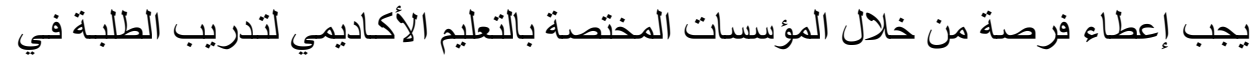

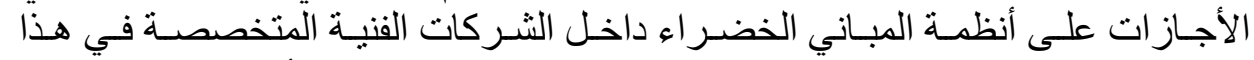

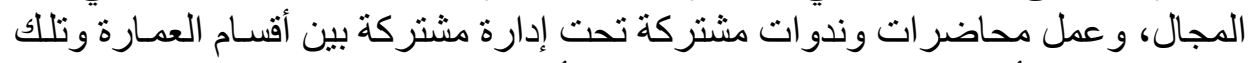

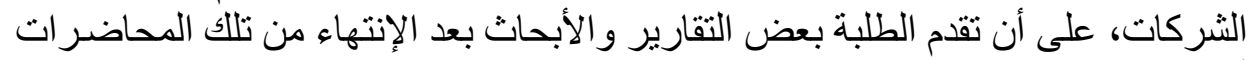

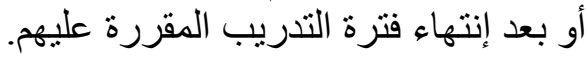
r ) على مستوى المصممين المعماريين:

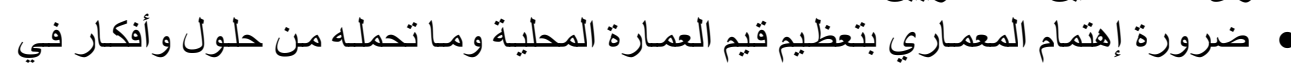

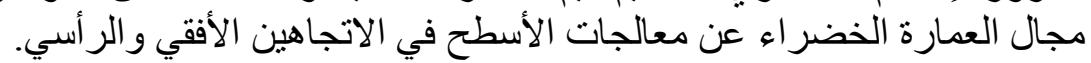

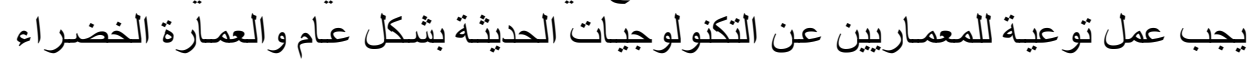

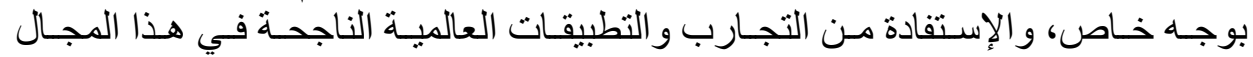

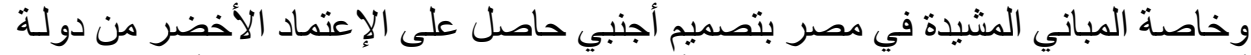

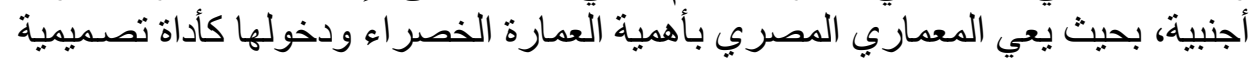

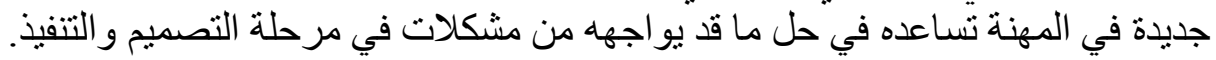

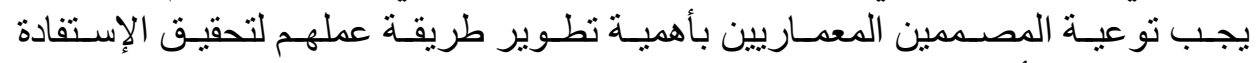

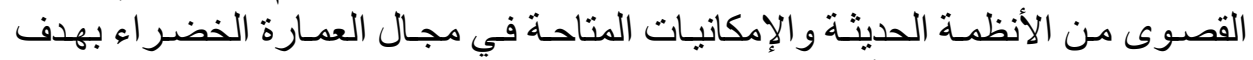

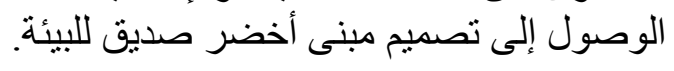
r) على مستوى المراكز والمؤسسات البحثية:

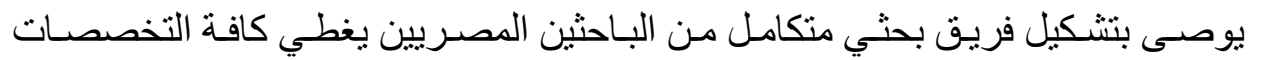

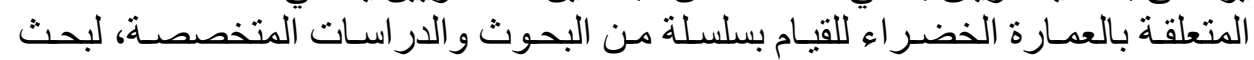

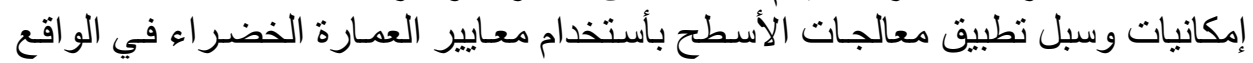

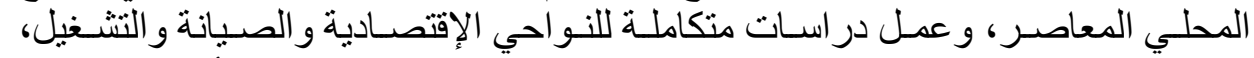
وبحوث تدريب للمهندسين و العاملين و الفنيين لإعداد كو ادر فنية تستطيع أن تتولى تنفيذ وتشغيل تللك النوعية من المباني المصرية.

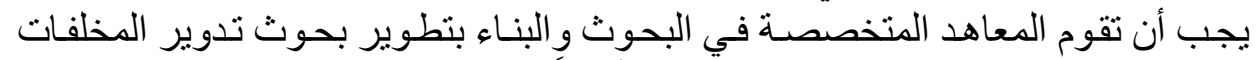

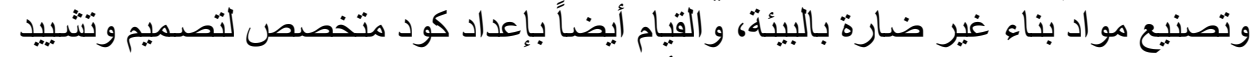

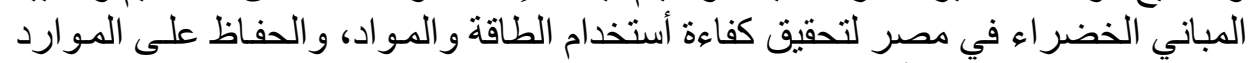

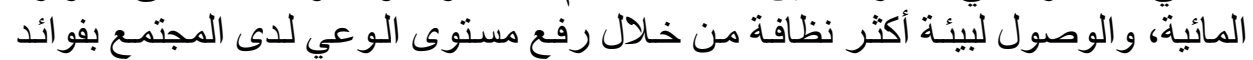
المباني ذات التأثثر المنخفض على البيئة. 


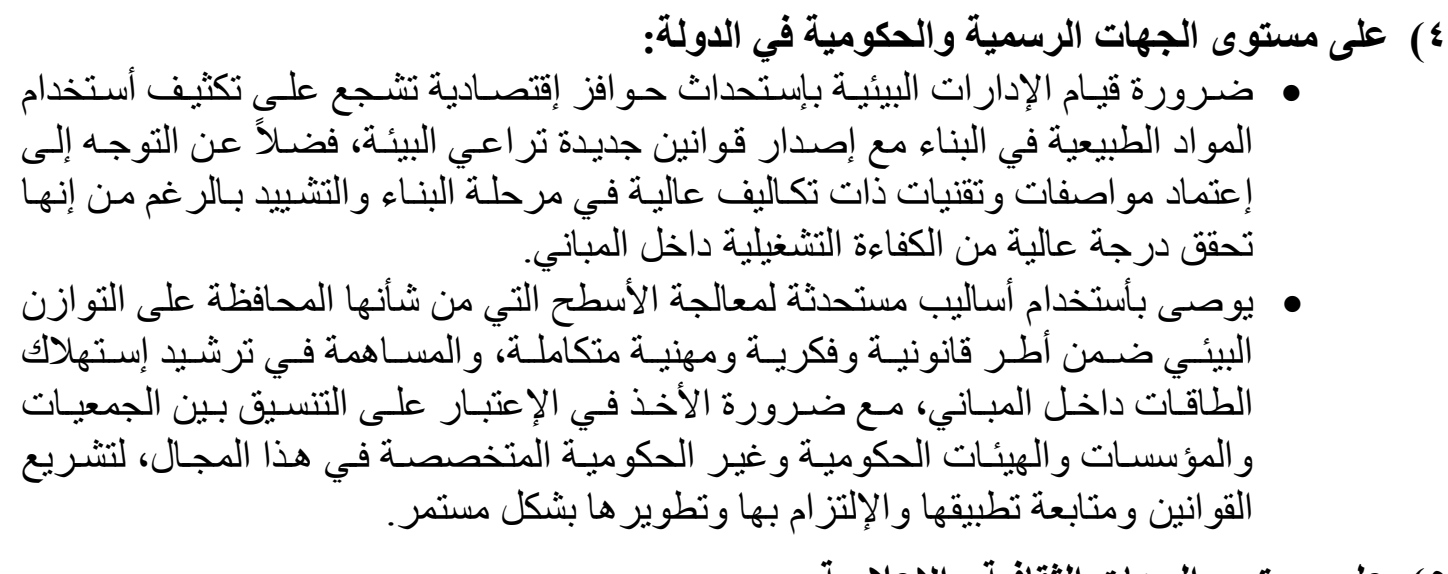

•) على مستوى الجهات الثقافية والإعلامية:

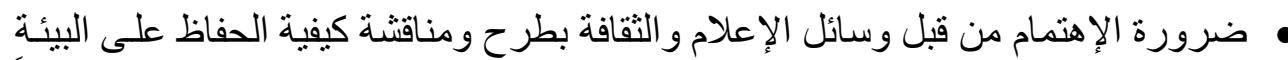

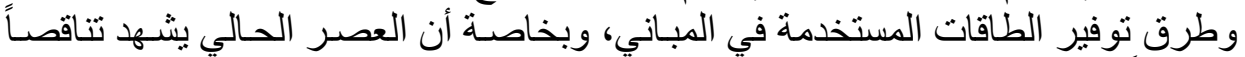
ملحوظاً في مصادر الطاقة غير المتجدة.

يجب أن يتم العمل على زيادة التوعية والإعلان عن فكر معالجات الأسطح في الاتجاهين

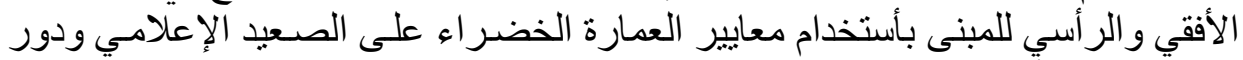

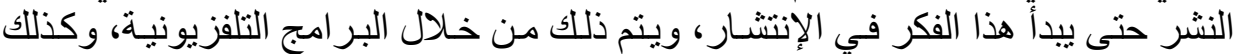

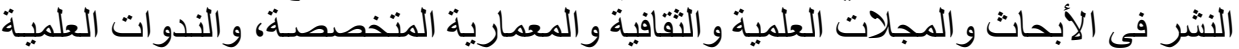

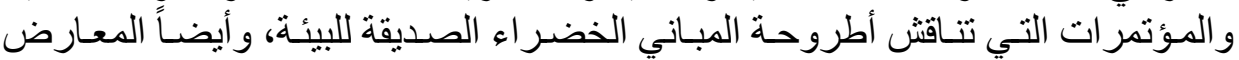
المحلية والعالمية التي تقام في مصر بشكل مستمر.

1) URL: https://inhabitat.com/editt-tower-by-trhamzah-and-yeang, accessed:

December 3, 2020, 4:00 PM.

2) URL: http://www.trhamzahyeang.com, accessed: December 5, 2020, 10:00 AM.

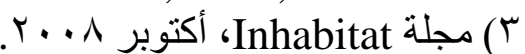

4) David Gissen, "Big and Green: Towards Sustainable Architecture in the 21st

Century", Priceton Architectural Press, New York and National Building Museum, Washington, 2003, p.106 - p.108.

5) Asmaa Mahmoud Abo Serie Shaarawy, "Bioclimatic Skyscrapers", M. Sc

Thesis, Architecture Department, Cairo University, 2008, p.389.

6) Ivor Richards, "Ecology of the sky", The Images Publishing Group Pty Ltd, Australia, 2001, p.114: 116.

7) URL: http://www.archdaily.com/90356/boston-fusion-bay-arch, accessed:

December 10, 2020, 5:00 PM.

8) URL: https://inhabitat.com/dazzling-checkerboard-green-roof-brings-thecountryside-to-south-bosto/, accessed: December 16, 2020, 4:00 PM.

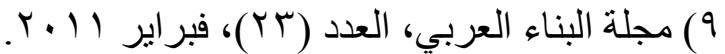

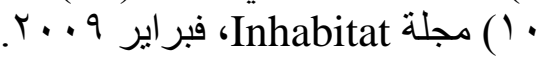

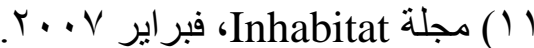

12) URL: http://www.domusweb.it/en/architecture/2010/05/17/-very-greenutopias.html, accessed: December 29, 2020, 11:00 PM. 